\title{
EXPERIMENTAL TESTS OF THE SPATIOTEMPORAL SCALE OF SEED PREDATION IN MAST-FRUITING DIPTEROCARPACEAE
}

\author{
L. M. CURRAN ${ }^{1,3}$ AND C. O. WebB ${ }^{2}$ \\ ${ }^{1}$ Department of Biology and School of Natural Resources and Environment, University of Michigan, \\ Ann Arbor, Michigan 48109-1048 USA \\ ${ }^{2}$ The Arnold Arboretum of Harvard University, Cambridge, Massachusetts 02138-2094 USA
}

Abstract. Mast-fruiting Dipterocarpaceae exhibit highly synchronous, interspecific seedfall at irregular, multiyear intervals. To investigate how the temporal pattern of seedfall affects dipterocarp seed and seedling survival, in both a logged and a primary lowland tropical forest, we planted Shorea stenoptera Burck seeds in the last three weeks of a 12wk synchronous dipterocarp seedfall during a major community mast-fruiting event in West Kalimantan, Indonesia. As a result of commercial timber harvest of dipterocarp individuals eight years before, total dipterocarp seed production in the logged site was only $23 \%$ of that in the primary forest. At both sites, an average of $35 \mathrm{~kg}$ of seed was sown across a large area $\left(\geq 1 \mathrm{~km}^{2}\right)$ to examine the spatial pattern of seed destruction. During the period in which "natural" community mast seed was available to predators, $92 \%$ and $99 \%$ of experimentally sown seed escaped predators in logged and in primary forest, respectively. After regional seed resources were exhausted, nomadic vertebrates (primarily the bearded pig, Sus barbatus) were observed in both forest areas, and all ungerminated seed was destroyed. Seed predators arrived earlier in the logged area, before most experimentally sown seed had germinated, and the logged site experienced greater seed loss to vertebrates than did the primary forest. Because nomadic seed predators were absent during peak fruit fall of naturally occurring communities at both study sites, there was no evidence of local predator satiation. Rather, experimentally sown seed escaped predation because of rapid germination before predator arrival, as opposed to being ignored by satiated predators. Seed escape was more dependent on the late arrival of pigs than on the amount of local seed production. There was no significant spatial autocorrelation of seed predation. All remaining seed at the scale of the experiment $\left(>1 \mathrm{~km}^{2}\right)$ was destroyed by predators. These findings suggest that satiation of nomadic predators occurs at the landscape scale.

Postdispersal seed predators caused significantly greater seed destruction in the experimentally sown seed populations than in naturally dispersed, mast-fruiting communities at both sites. In both logged and primary forests, there was significantly greater loss of experimentally sown seed to predation than was found in the entire natural mast-fruiting Shorea community combined (21 spp.). Moreover, a naturally occurring, but late-fruiting, Shorea species also exhibited greater seed losses to predation than did all other species within each mast-fruiting community, and these proportional losses were similar to those observed in the experimentally sown seeds.

Seeds that escaped predation and vertebrate herbivory on post-establishment seedlings displayed high survival, indicating that the availability of suitable microsites did not limit recruitment. In the primary forest, $65 \%$ of the germinated experimental seed that survived early causes of mortality was alive 40 mo post-planting, which coincided with the next mast-fruiting event. The spatial distribution of these seedlings was modified primarily by the foraging behavior of vertebrate seed predators in the first two weeks post-planting. The influence of vertebrate predation on seed and seedling survival suggests that foraging behavior by terrestrial vertebrate seed predators may cause directional and/or stabilizing selection for synchronous, interspecific supra-annual dipterocarp seed production across forest regions in Kalimantan.

Key words: commercial logging; Dipterocarpaceae; herbivory; mast fruiting; phenology; predator satiation; reproductive synchrony; seed predation; seedling recruitment; Shorea stenoptera; stabilizing selection; Sus barbatus.

\section{INTRODUCTION}

A central question in plant ecology concerns the relative importance of postdispersal seed predation, microsite availability, and seedling herbivory as potential

Manuscript received 16 March 1998; revised 18 December 1998; accepted 29 December 1998; final version received 5 February 1999.

${ }^{3}$ E-mail: 1curran@umich.edu selective forces that limit plant population recruitment (Grubb 1977, Harper 1977, Crawley 1983, 1989a, b, Taylor 1984, Fenner 1985, Andersen 1989). Although damage by seed predators and herbivores may be important to individual fitness (Janzen 1971a), the impact may be less consequential to populations if plant recruitment is also limited by processes at subsequent life history stages (Harper 1977). A few studies have established the effects of seed predation on plant pop- 
ulation dynamics (Louda 1982a, b, Duggen 1985, Smith 1987, Smith et al. 1989, Eriksson and Ehrlen 1992), and seed predation may yet be a major component in a suite of interacting factors that affect seedling recruitment (Borchert et al. 1989). These factors may be highly variable on different spatial and temporal scales (Levin 1992).

It has been suggested that mast fruiting, or episodic synchronous reproduction by a population or a community of tree species, evolved as a reproductive strategy to satiate seed predators (Salisbury 1942, Janzen 1974, Harper 1977, Waller 1979, Silvertown 1980). Species of Dipterocarpaceae of the Malesian region (Borneo, Sumatra, and Peninsular Malaysia) not only exhibit "strict" masting (sensu Kelly 1994), but also interspecific, community-wide reproductive events (Ashton et al. 1988, Curran 1994; Curran and Leighton 2000). A study of Dipterocarpaceae seed production spanning various spatial scales revealed that vast quantities of seed $(191.0 \pm 45.6 \mathrm{~kg} / \mathrm{ha}, \bar{X} \pm 1 \mathrm{SE})$ from 48 sympatric species (five genera) were produced synchronously in 1991 across six vegetation types, mountain valley systems, and large forested areas (Curran 1994, Curran and Leighton 2000). Moreover, $>95 \%$ of all dipterocarp seedfall occurred in two 6-wk events out of the 520-wk period from 1986 to 1996 (L. M. Curran, unpublished data). This marked reproductive synchrony suggests that selective forces may act across large spatial scales and across taxonomic levels.

The Janzen-Connell spacing model of tree species diversity has been tested either on sown or on naturally dispersed seeds and seedlings in neotropical forests, by measuring predator and herbivore damage at the level of individual trees (Janzen 1970, Connell 1971, Clark and Clark 1984, Sork 1987, Schupp 1988, Kitajima and Augspurger 1989, Augspurger and Kitajima 1992, Howe 1993, Terborgh et al. 1993, Burkey 1994, Notman et al. 1996). Of the few temperate or tropical studies that placed seed away from parental tree seed shadows (Webb and Willson 1985, Schupp 1988, Schupp and Frost 1989, Whelan et al. 1991, Eriksson and Ehrlen 1992, Notman et al. 1996), only Schupp (1992), Losos (1995), and Hart (1995) have distributed seeds throughout a large area to examine patterns of seed predation at the population level. Detection of scaledependent processes depends not only on how the focal organisms respond to resource patchiness and seed availability, but also on whether the sampling has been structured in a manner that is sensitive to these dynamics (Wiens et al. 1986, Addicott et al. 1987, Wiens 1989, Hanski 1991, Pickett et al. 1994). Issues of spatiotemporal variation and research design are of concern in studies of mast-fruiting species in general (e.g., Ostfeld et al. 1996), and to interspecific, mast-fruiting dipterocarp communities in particular.

Van Schaik et al. (1993) remarked that tests of adaptive hypotheses of phenological behavior usually must rely on comparisons (Aide 1988) or on coincidences
(Janzen 1975) between phenological change and the proposed selective factors. Unfortunately, an experimental approach is rarely possible (Crawley 1989b; but see excellent studies by Augspurger 1980, 1981). In 1991 , an event occurred that provided a highly unusual opportunity to manipulate dipterocarp fruit fall phenology: a population of Shorea stenoptera Burck produced considerable viable seed late in the mast-fruiting period. Because seeds germinate within a week and cannot be stored, this seed source was critical for our experiment by providing large quantities of undamaged seed late in the community fruit fall period. An experimental test of the predator satiation hypothesis in both logged and primary forest sites was facilitated through this manipulation of the timing and placement of seedfall of a mast-fruiting canopy tree. Thus, viable S. stenoptera seed was made available to predators and herbivores after $96 \%$ of dipterocarp seeds in each community had fallen and after the great majority of those had germinated.

As an experimental test of predator satiation, this opportunity was unique. First, seeds were sown across large areas that mirrored those of the community-wide fruit fall. Second, the experimental plantings created a controlled experiment in which the temporal availability of dipterocarp seed was shifted by just 7-10 d. Third, large quantities of viable seed were placed in each forest. Fourth, simultaneous examination of a logged and a primary forest, the effects of the density and distribution of reproductive trees and, thus, seed production could be contrasted. Fifth, seedfall, mortality, and establishment for the "natural" mast-fruiting dipterocarp community (21 spp.) were monitored at both sites and available for comparison with the experimental findings. Sixth, one naturally occurring species that dispersed seed throughout the mast-fruiting period also continued to disperse seeds in the tail of the seedfall distribution, when experimental seeds were sown. This allowed comparison of data obtained from the experimentally sown species with a naturally "late-" fruiting species in each forest site.

\section{Objectives}

This study had four major objectives. Although seed predators were monitored throughout the mast event, nomadic vertebrates were absent from both study sites before seed additions. The first objective was to determine the density and the impact of terrestrial vertebrate seed predators in the region late in the fruit fall during this major mast event. The second was to identify the causes of seed and seedling mortality for up to 34-wk after dispersal, as well as any variability of these causes in time and space. The third was to contrast the findings from experimentally sown seed with observations from the "natural" dipterocarp communities, both in "peak-" and "late-" fruiting species. The fourth was to contrast the mortality of natural and experimentally sown seeds and seedling survivorship by 
comparing the Gunung Palung (GP) National Park with Sungai Matan (SM) logged forest.

The following questions were addressed.

Within each forest type: logged and primary forest:

1) Do postdispersal seed predators exist in dipterocarp forest and could their actions potentially select for the observed synchrony of dipterocarp fruit fall?

2) What are the temporal and spatial patterns of postdispersal seed predation by vertebrates and insects? Do these patterns reflect the observed temporal and spatial scale of community-wide synchrony of dipterocarp fruit fall?

3) Is vertebrate and insect postdispersal seed predation the major source of mortality affecting the establishment of S. stenoptera seedlings? How may herbivores and microsites modify the effects of postdispersal predation? If seeds escape predation, is herbivory or microsite quality limiting seedling establishment?

Site comparison: logged and primary forest:

4) Do forests logged $8 \mathrm{yr}$ before the 1991 mastfruiting event differ from primary forests in their capacity to satiate dipterocarp seed predators?

5) Does the logged forest differ significantly from the primary forest in the impact of herbivores, susceptibility of seedlings to drought stress, and/or the availability of suitable seedling microsites for the experimentally sown seeds?

Phenological or temporal comparison: masting and late-fruiting populations:

6) Do experimentally sown and naturally late-fruiting populations (within each community) differ significantly from "natural" mast-fruiting populations in the relative amount of seed predation, herbivory, seedling establishment, and survivorship?

\section{Natural history of the focal species, postdispersal seed predators, and herbivores}

Experimental seed.-Shorea stenoptera (Dipterocarpaceae: sect. Pachycarpae) was used for a planting experiment for several reasons. First, S. stenoptera was available from locally managed village forests in the Sungai Matan timber concession and near the Gunung Palung National Park, and had considerable seed production unusually late in the regional fruit fall period. Thus, large amounts of viable $S$. stenoptera seeds were available for transplantion to both sites. Because $S$. stenoptera has not been found growing naturally at either study area, we could sow even distributions and densities of S. stenoptera, and could easily monitor the distinctive seeds and seedlings. Natural stands of $S$. stenoptera occur northeast of the study area.

Postdispersal vertebrate seed predators. - The most prominent postdispersal seed predator was the bearded pig (Sus barbatus barbatus). Bearded pigs are large (100-200 kg), nomadic vertebrates with a fluid group structure that can consist of hundreds of migrating individuals (Pfeffer 1959, Caldecott 1986, Curran 1994). Pigs eat and crush any ripe seed, but avoid germinated seed.

Nocturnal rats are also common in Bornean forests. The most abundant rodent seed predators are the red spiny rat (Maxomys surifer), the brown spiny rat (Maxomys rajah), and Whitehead's spiny rat (Maxomys whiteheadi). Other large-bodied rats, such as the longtailed giant rat (Leopoldamys sabanus) and Muller's rat (Sundamys muelleri), may eat large dipterocarp seeds. Spiny rats typically remove a single dipterocarp seed per foraging trip, leaving sepals and chewed testas with incisor marks. In captive feeding trials, spiny rats rejected dipterocarp seeds containing high levels of insect attack, and also avoided germinating seed. Spiny rats larderhoard seeds in deep, underground burrows, although the seeds must be eaten immediately because dipterocarps germinate rapidly. Seeds do not establish in burrows. Seed manipulations and detailed vertebrate observations during three mast events from 1985 to 1993 did not document any vertebrates that scatterhoard dipterocarp seeds (Curran 1994). Dipterocarp seed morphology and ecology predict these observations, because all seeds possess thin testas and display rapid germination.

Other potential postdispersal dipterocarp seed predators are the common porcupine (Hystrix brachyura) and the long-tailed porcupine (Trichys fasiculata). These two species have not been observed removing dipterocarp seeds, but the possibility remains that some seed predation not attributable to spiny rats might be due to porcupines.

Postdispersal invertebrate seed predators.-Bark beetles (Scolytidae: Coccotrypes spp.) attack dispersed seeds of all dipterocarp species and appear to be dipterocarp generalists (Browne 1961, Daljeet-Singh 1974; L. M. Curran, unpublished data). Seeds of species within the section Pachycarpae appear to be highly susceptible to bark beetle attack. Preliminary trials that placed S. stenoptera seeds in primary forest indicate that Coccotrypes spp. located some seeds within 1-3 $\mathrm{d}$ of sowing. Bark beetles mate and brood multiple generations within a single seed. Seeds may germinate with low levels of infestation, but destruction of the embryo or emerging radicle kills the seed. Cotyledons of established seedlings frequently have scolytid damage, which would be expected to reduce seedling reserves.

Vertebrate herbivores.-The most common and destructive browsing herbivore in primary forests is the barking deer (Muntiacus muntjac). Although they have been observed in the protected forest year-round, sightings have increased during mast-fruiting seasons. Barking deer browse primarily on the first pair (or pairs) of leaves, destroying young dipterocarp seedlings by eating the apical meristem.

Other vertebrates, e.g., sambar deer (Cervus unicol- 
or), greater and lesser mouse deer (Tragulus javanicus and T. napu, respectively), and porcupines also may browse on dipterocarp seedlings, but there are no recorded observations. If any of these agents browses dipterocarp seedlings, this herbivory cannot be readily distinguished from that of the barking deer. Therefore, herbivory damage was grouped into broad classes of vertebrate or invertebrate herbivory.

Invertebrate herbivores. - Shoot borers, leaf rollers, leaf miners, orthopterans, and a diversity of unidentified species were located on $S$. stenoptera seedlings and other dipterocarps. Although insect herbivores from $S$. stenoptera were not reviewed by taxonomists, field observations did not identify any major destructive insect species found solely on S. stenoptera.

Fungal pathogens.-Although fungal pathogens in the genera Fusarium, Cylindrocarpon, Pythium, and Cylindrocladium have been reported on dipterocarp seedlings, both in plantations and in nearby natural populations (Elouard 1991, Smits et al. 1991), none was observed to cause direct mortality of experimental seedlings in this study.

\section{Methods}

\section{Study sites, West Kalimantan, Borneo}

This study was conducted between January 1991 and January 1994 as part of a larger investigation monitoring from March 1985 to September 1998. The Sungai Matan (SM) commercial timber concession (60000 ha) is separated from the northeast boundary of the Gunung Palung (GP) National Park (90000 ha; $1^{\circ} 13^{\prime}$ $\left.\mathrm{S}, 100^{\circ} 7^{\prime} \mathrm{E}\right)$ by a wide $(\sim 50-300 \mathrm{~m})$, perennial river, Sungai Matan (Curran and Leighton 2000). The logged research area is $\sim 5-7 \mathrm{~km}$ from the river and park border. Although paired research sites were only 25-30 $\mathrm{km}$ apart, each site occupied a distinctive watershed. Mean annual rainfall is $4500 \mathrm{~mm}$, with June through September generally being drier than other months. A full description of the primary forest research site in the Gunung Palung National Park is provided in Curran (1994).

At the logged research site, timber harvest was completed in 1982-1983, four and eight years before the 1987 and 1991 regional mast-fruiting events, respectively. Only commercial dipterocarps $(>59 \mathrm{~cm} \mathrm{dbh})$ had been harvested from the selected site. This coupe, or work block, did not receive any pre- or post-harvest silvicultural treatments. Field surveys of $>35 \%$ of the West Kalimantan timber operations (occupying $\sim 2 \times$ $10^{6}$ ha of production forest) revealed that the logged forest study area is representative of current dipterocarp harvesting practices throughout the province (Curran 1992). The harvested site had thus received only one prior "treatment" differentiating it from GP: the removal of canopy dipterocarps.

\section{Density of reproductive dipterocarps}

To permit comparisons of local and regional predator satiation, we assessed the density and basal area of adult-size dipterocarps and the proportion of reproductive dipterocarps at both sites. Adult dipterocarp density and reproductive response was assessed on randomly selected transects $(100 \times 30 \mathrm{~m}$; stratified $\geq 150$ $\mathrm{m}$ apart to insure independence), both at GP $(n=17)$ and at SM $(n=16)$. An additional five transects in an unharvested forest within the logging concession served as a local control $(n=5)$ to the logged site. Within transects, all dipterocarp trees $>29 \mathrm{~cm}$ dbh were tagged, measured (dbh), identified to species, and monitored semi-monthly for reproductive output. Density and basal area of reproductive dipterocarps were calculated from adult trees $(>49 \mathrm{~cm} \mathrm{dbh})$. Monitoring of the SM logged site involved some variation on this method. From a central skid trail or branch road, 18 perpendicular transects $(250 \times 30 \mathrm{~m})$ were randomly selected in a stratified design (150 m apart), and all dipterocarp trees $>19 \mathrm{~cm}$ dbh were tagged, identified, and monitored for reproductive activity. All dipterocarp stumps found within these transects were plotted, measured, and identified to one of the five dipterocarp genera or subsections of Shorea. Several species could be recognized by stump characteristics. These initial transects were assessed to determine whether extraction levels differed with distance from the branch road or central skid trail. Because no significant differences in extraction levels were found, we randomly chose subsections of these transects equivalent in scale to those used at the GP site $(100 \times 30 \mathrm{~m})$.

\section{Seed production, predation, and herbivory on naturally dispersed seed}

The second, third, and fourth censuses were conducted simultaneously with surveys of seed production, herbivory, and seedling establishment of all naturally occurring dipterocarp species at both sites. Transects $(100 \times 30 \mathrm{~m})$ were randomly selected (stratified $\geq 150$ $\mathrm{m}$ apart to insure independence), both at GP $(n=17)$ and at SM $(n=16)$. An additional five transects in an unharvested forest within the logging concession served as a control $(n=5)$ by assessing the seed production and establishment in primary forest adjacent to the logged sites.

Throughout each transect, $101-\mathrm{m}^{2}$ plots were systematically placed every $10 \mathrm{~m}$, alternating perpendicular direction and distance from the center line $(5 \mathrm{~m}$ and $10 \mathrm{~m}$ ). The GP site contained a sample of 1701 $\mathrm{m}^{2}$ plots, whereas the SM site had $1601-\mathrm{m}^{2}$ plots in the logged forest and an additional $501-\mathrm{m}^{2}$ plots in the unharvested SM control site. In each of the 380 1$\mathrm{m}^{2}$ plots, all seeds and seedlings (tagged with numbered toothpicks) were identified to species (Webb and Curran 1996); the cause of seed destruction and levels of herbivory were recorded for each individual. All immature and mature seeds were identified to species. Seed damage by arboreal and terrestrial vertebrates was determined from fruit remains for the entire mast event (three months). For each forest type (primary, GP; 


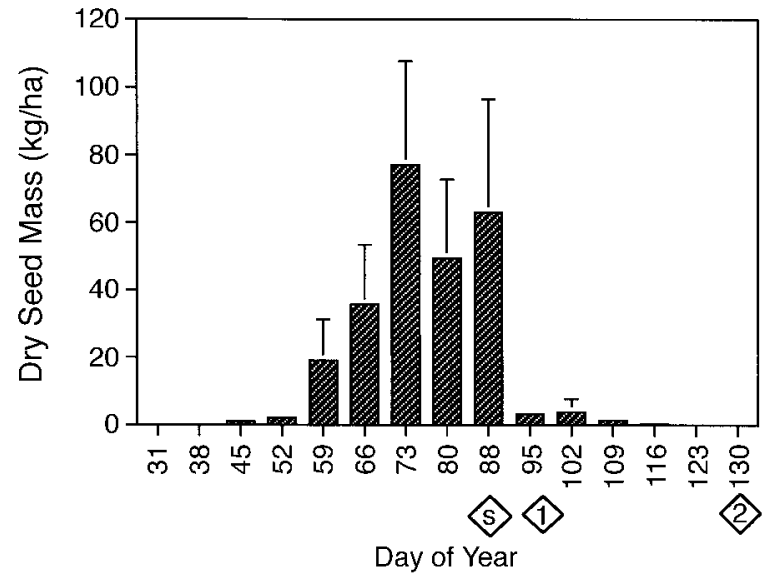

FIG. 1. Temporal pattern of viable dipterocarp seedfall with the experimental planting and census dates. The GP lowland sandstone forest formation is shown. Viable seed falling $\left(\mathrm{kg} \cdot \mathrm{ha}^{-1} \cdot \mathrm{wk}^{-1}\right)$ was calculated from fruit fall traps (total collecting surface of $146.9 \mathrm{~m}^{2}$; see Curran 1994). Diamonds indicate the date of sowing (S) and the first (1) and second (2) census. Error bars indicate $+1 \mathrm{SE}$.

logged, SM; and unlogged control, SM-CON), the 10 plots or replicates were combined for each transect, and transects were then averaged for each forest type. This baseline measure provides information on the natural rates of seed production, seed predation, seedling herbivory, and seedling survival in the dipterocarps.

\section{Experimental seed placement design}

Site selection in GP.-The most ecologically similar congener of Shorea stenoptera is Shorea pinanga Scheff sect. Pachycarpae, and this species was reproducing and regenerating in lowland sandstone forest at GP. This forest occupies (at 15-150 m a.s.1.) a deep clay-rich podzolic soil on a sedimentary substrate that has a relatively high moisture retention capacity. Natural stands of S. stenoptera are found northeast of the study area in lowland sandstone forests. Therefore, lowland sandstone forest was selected as the most ecologically suitable forest type in which to place seeds of $S$. stenoptera to evaluate predation levels and seedling establishment. The suitability of this forest type was assessed through comparisons of S. stenoptera and $S$. pinanga in terms of the spatial and temporal pattern of seed loss and seedling mortality for this closely related congener of the experimentally sown species.

Timing of seed placement.-All seeds were distributed in one day in the tail of the community-wide, mastfruiting temporal distribution. Fig. 1 displays the temporal pattern of viable seedfall (in dry mass per hectare per week) for the sandstone forest, with seed sowing and census dates. Seeds were placed on the ground to mimic wind and gravity dispersal. They were not planted in the ground. To minimize extraneous unnatural influences, seeds were placed $\geq 8 \mathrm{~m}$ from trails.

Arrangement of planted seeds at SM.-Fourteen ran- domly stratified $(\geq 200 \mathrm{~m}$ apart $)$ transects $(250 \times 10$ $\mathrm{m})$ were established throughout a $2 \mathrm{~km} \times 500 \mathrm{~m}$ coupe or work block area. In total, 690 seeds were distributed across the 4 ha of transects. Two sites were rejected because they traversed streams or swamps. Seeds were placed in "clumps" of five, with seeds spaced $\sim 15 \mathrm{~cm}$ apart. Clumps were located every $25 \mathrm{~m}$ along the transect and were located $8 \mathrm{~m}$ from the center of the transect in alternating perpendicular directions. There were 10 replicates of seed clumps per transect, totaling 50 seeds per transect. The logged forest received a total of 33 $\mathrm{kg}$ of sown seed. Each of the 13 transects contained an average of $2.4 \mathrm{~kg}$ of seed, and one water-logged transect received only $1.9 \mathrm{~kg}$. Thus, $9.5 \mathrm{~kg}$ of seed/ha were placed in the planted transects, resulting in an overall increase in dipterocarp seed biomass of 0.33 $\mathrm{kg} / \mathrm{ha}(0.98 \%)$ over the entire sampled forested area (100 ha).

Arrangement of planted seeds at GP.-Sixteen randomly stratified $(\geq 200 \mathrm{~m}$ apart $)$ transects $(250 \times 10$ $\mathrm{m})$ were selected across two valley systems with a river (6-30 m wide) separating the two mountain valley complexes. Eight transects were chosen in each of two disjunct sandstone forest areas. Seed placement was approximately equal in area to that of the logged forest site, as was the spatial dimension: $2 \mathrm{~km} \times 600 \mathrm{~m}$. Using an experimental array similar to that described for SM, we distributed a total of $38 \mathrm{~kg}$ of seed across the 16 sites (795 seeds), with each transect containing a mean of $2.4 \mathrm{~kg}$ seed or $9.5 \mathrm{~kg} / \mathrm{ha}$. Thus, the total forested area sampled received an additional mean $0.32 \mathrm{~kg}$ seed/ ha, or an increase of $0.22 \%$.

\section{Monitoring experimentally sown seeds and Shorea stenoptera seedlings}

At both sites, seeds and seedlings were censused at five stages of seed maturation and seedling establishment:

1) First census, 1 wk post-sowing. This census coincided with the tail of mast-fruiting of the dipterocarp community, in which ripe dipterocarp seed was still generally available in the forest (Fig. 1).

2) Second census, 7 wk post-sowing. All surviving seeds had germinated by this time, but seedlings would be expected still to be exhausting parental cotyledon reserves (Fig. 1).

3) Third census, 14 wk post-sowing. Seedlings would be expected to be fully independent from parental resources in cotyledons, with growth being dependent on light and soil (i.e., microsite) conditions. Ectomycorrhizal fungi should have established by the time of this census (Alexander et al. 1992).

4) Fourth census, 34 wk post-sowing. This census was conducted immediately following a 3-mo regional drought that occurred in August-November 1991, and is coincident with the onset of rains.

5) Fifth census, 160 wk post-sowing. This census was conducted only at GP, because the SM transects 
had been destroyed unexpectedly by illegal relogging. This census also coincided with the next community mast-fruiting event at GP.

\section{Seed and seedling measurements}

In each census, the number of seeds and seedlings remaining was recorded, along with a description of the forest site (i.e., dense underbrush, skid trail) and broad classification of the light regime (i.e., open, new gap, or shaded understory). If seeds were damaged or partially eaten, the agent was determined from the remains. Seedlings were tagged and height was measured at the apical meristem and at the tallest leaf. We noted the number and condition of cotyledons and whether a seedling was trampled, broken at the stem, or eaten below the meristem. To assess herbivory, we recorded the number of leaves, the percentage of each leaf lost to herbivory, and the number of leaves removed, as well as insect agents and patterns of leaf damage. After the major drought (before the fourth census), the presence of seedling stalks and condition of dried leaves were described to assess the drought as a source of mortality.

Because of the natural history of this mast-fruiting community, there are some experimental limitations with this study. Ideally, we would plant the experimental species in the early, peak, and late weeks of the community fruit fall distribution. Because of the rapid germination and lack of sufficient quantities of viable seed available out of community synchrony, this is impossible. Even if sufficient seed were available, however, we would predict that all experimentally sown seed in the early and peak periods would have germinated, because terrestrial vertebrate seed predators were not observed at any of the sites before the experimentally sown seeds were distributed in the late tail of the fruit fall distribution. Also, selection of the experimental species was dictated by availability of large quantities of viable seed, rather than by targeting a species with seed size in the midrange of the entire dipterocarp community. Because terrestrial seed predators were observed to eat all available seed during a minor mast (Curran and Leighton 2000), and naturally late-fruiting, but small-seeded, species were disproportionately destroyed during this experiment, seed size was not perceived to be a major factor influencing the foraging behavior of seed predators.

\section{ANALYSES}

\section{Site and agent comparisons}

Each clump of five seeds was treated as a single replicate, with 10 such clumps being replicates within each independent sample (i.e., transect). To evaluate differences between primary and logged forests, all transects were combined and treated as a forest sample. Randomization contingency tests (1000 or 10000 runs) were applied to test the null hypothesis that forest types (logged and primary) or communities (experimental and natural) did not differ in the number of clumps damaged per transect, the number of transects, and/or the percentage of seeds destroyed by various agents (Pyke and Thompson 1986).

To compare the two separate ridge systems within the protected forest, eight transects in each ridge complex $(n=16)$ were examined with ANOVAs. Also, transects were assigned as "ridge-top" or "slope-tranversing" sites and as primarily wet or dry. These were compared using two-factor ANOVAs. Numbers of seeds destroyed, clumps found, and leaf area lost to herbivory were arcsine-transformed to normalize variances for analyses. Counts were log-transformed. Multivariate analysis of variance (MANOVA) was applied to test whether seedling survivorship between the second to third or third to fourth censuses was associated with the independent variables seedling height, number of leaves, and herbivory levels. All univariate and multivariate ANOVAs were carried out using SuperAnova software (Abacus Concepts 1989). Other statistical analyses were performed with SYSTAT software (SYSTAT 1992). Randomization software was written and compiled in C for MS-DOS.

\section{Mortality rates}

At both forest sites, the percentage of survivors, the instantaneous mortality rate at each census and the mean mortality rates were calculated over the $34 \mathrm{wk}$ of this study for the experimentally sown seeds, for the congener Shorea pinanga, and for the natural mastfruiting dipterocarp seed community. Mean and instantaneous mortality are expressed as weekly rates. For the GP population, this was extended to $160 \mathrm{wk}$ post-planting. Mean instantaneous mortality rate $\langle\lambda\rangle$ was calculated (sensu Sheil and May 1996) from the instantaneous rates of each interval as $\langle\lambda\rangle=\Sigma p_{i} \lambda_{i}$, where $p_{i}$ is the percentage of those that died in the interval of all of those that died. $\lambda_{i}$ is the instantaneous mortality rate for interval $i$, with $\lambda_{i}=\ln \left(N_{i} / N_{0}\right) / t$, where $N_{0}$ is the number surviving at the beginning of the interval, $N_{i}$ is the number at the end of the interval, and $t$ is the length of the interval (in weeks).

Differences in mean or instantaneous mortality rates between populations were assessed through 1000 permutations of individuals across populations. That is, each permutation compared two populations identical in size to those being assessed; membership in a population was randomly determined, however. The tail distribution $(P)$ was the frequency with which permutations achieved a difference in mortality greater than or equal to the difference observed. Within each population, the significance of deviation from $\langle\lambda\rangle$, the mean mortality rate (Sheil and May 1996), for each instantaneous rate at each census interval was assessed in comparison to expectations from 1000 Monte Carlo simulations using the formula $N_{e}=N_{0}\left(e^{-\langle\lambda\rangle t}\right)$, where $N_{0}$ is the number surviving at the start of the interval, and 
$t$ is the interval duration in weeks. The tail distribution $(P)$ was the frequency at which $N_{e}$ was $\geq$ or $\leq$ the actual number surviving at the end of the interval. Software for permutations and Monte Carlo simulations was written and compiled in $\mathrm{C}$.

\section{Spatial analyses}

Because the diverse agents that destroy tropical seed operate on different spatial scales (Hallwachs 1986, Schupp 1988), seed addition experiments require testing the spatial association of seed or seedling destruction by specific agents. Tests of spatial autocorrelation have been applied to assess statistical independence at various experimental levels (Sokal and Oden 1978a, b). Spatial autocorrelation can also be used as a descriptive statistic to estimate the scale of patchiness in the system and to search for processes that may produce such patterns (Davis 1993, Moloney 1993, van Es 1993). Here, tests for spatial autocorrelation were applied to data obtained from the experimentally sown transects in order to assess statistical independence in seeds, replicates, and transect samples, as well as to examine spatial patterns in seed and seedling mortality that might be explained by vertebrate foraging behavior or by site.

To estimate patchiness of mortality, three spatial scales were examined: within clumps, within transects, and between transects within a site. First, the varianceto-mean ratio for each type of seed loss or agent was calculated for each seed clump, using the binomial distribution. Within transects, the variance-to-mean ratio of the number of seeds lost to each mortality source was calculated. Between transects, the variance-tomean ratio of the total number of seeds or seedlings lost due to each mortality source in each transect was assessed for all transects within a forest site.

Spatial analysis of autocorrelation was investigated for each category of mortality (e.g., total mortality, or predation by pigs, or seedling mortality) in two ways. First, to assess if seed or seedling loss in clumps was spatially nonrandom, runs analyses (permutations or randomizations) were applied to each transect independently. The clumps were considered only as mortality observed (1) or not observed (0) in runs tests along each transect to assess the hypothesis that the mortality was clumped. Second, the degree of mortality on a continuous scale $(0.00-1.00)$ was similarly assessed in terms of spatial autocorrelation. Data points obtained toward either end of a transect necessarily lacked information for autocorrelation beyond the bounds of the transect. With the 250-m transects, separation distances thus were calculated within $70 \%$ of the length of the spatial domain $(180 \mathrm{~m})$ to ensure sufficient sample sizes of the pairs or dyads at each distance (e.g., Clark 1979). The spatial autocorrelation of mortality as a function of distances of $30-180 \mathrm{~m}$ was examined for selected variables. The $30-\mathrm{m}$ spacing reflects the diagonal spacing between clumps placed 8 $\mathrm{m}$ from the center of the transect every $25 \mathrm{~m}$ on alternate sides of the transect. The rejection probabilities for each transect were combined for each site using meta-analysis techniques. To evaluate the statistical significance of the $\chi^{2}$ value, the transects $(n=14,16)$ at each site represent the degrees of freedom $(28,32$; see also Fisher 1958). Programs were written in Gauss (Aptech Systems 1993).

\section{RESULTS}

\section{Site differences in natural dipterocarp seedfall}

The logged (SM) and protected (GP) forest sites differed significantly in dipterocarp adult density, basal area, and seed production. Reproductive adult basal area in the SM site was limited to $2.17 \pm 0.22 \mathrm{~m}^{2} / \mathrm{ha}$ $(\bar{X} \pm 1 \mathrm{SE})$, or $16.7 \%$ of the control area (SM-CON) and $22.5 \%$ of the original stand (trees and stumps combined; Fig. 2). Basal area of reproductive dipterocarps in the logged forest was $17.2 \%$ of that in the reproductive sandstone forest in the GP protected site (Fig. $2 ; 12.64 \pm 1.32 \mathrm{~m}^{2} / \mathrm{ha}$ ). Dipterocarp viable seedfall in the SM logged forest, as seed dry mass, was $33.79 \pm$ $9.37 \mathrm{~kg} / \mathrm{ha}$, or $16.3 \%$ of the unharvested control SMCON sample (Fig. 2; $207.04 \pm 25.26 \mathrm{~kg}$ ). The GP protected sandstone forest produced viable dipterocarp seed dry mass of $145.98 \pm 23.15 \mathrm{~kg} / \mathrm{ha}$, or 4.3 -fold greater seedfall than the SM logged forest.

\section{First census}

Seed predation by pigs and rodents.-In the SM logged forest, 45 seeds (8.2\%) from 18 clumps (13\%) were destroyed by vertebrates. The GP protected forest lost six seeds $(0.8 \%)$ from four clumps $(2.5 \%)$. Vertebrate seed predation by bearded pigs alone or by small rodents and pigs together was significantly higher in the SM logged forest than in the GP protected site. Spiny rats or porcupines removed only a few scattered seeds at each site (three seeds at GP; five seeds at SM). The number of seed clumps with at least one seed damaged by a vertebrate differed significantly between the two sites $(P<0.0004)$. That is, the logged forest suffered more seed predation than the protected forest, both in terms of the number of clumps damaged by predators and the number of seeds removed. After the first week of seed availability, the protected forest (GP) still contained $37.2 \mathrm{~kg}$ of ripe Shorea stenoptera seed, whereas the logged forest had $30.6 \mathrm{~kg}$ of seed remaining.

\section{Second census}

At the second census, all viable seed had germinated, with some seedlings reaching $91-100 \mathrm{~cm}$ in height at both sites.

Vertebrate seed predation.-Bearded pigs destroyed seeds in all measured transects at the logged site and at the protected site. In GP, there were no significant differences in the percentage of seed clumps per tran- 
Reproductive

$\square$ Nonreproductive

$\boldsymbol{\Delta}$ Stumps
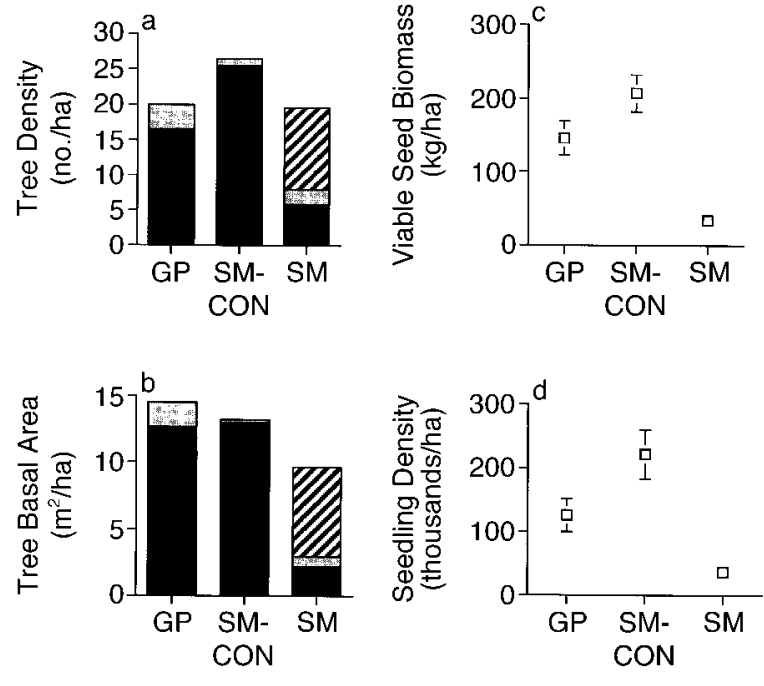

Site

FIG. 2. Site comparison of (a) density and (b) basal area of reproductive, nonreproductive, and extracted dipterocarp trees ( $>49 \mathrm{~cm} \mathrm{dbh),} \mathrm{(c)} \mathrm{biomass} \mathrm{(dry} \mathrm{mass)} \mathrm{of} \mathrm{viable} \mathrm{dip-}$ terocarp seeds, and (d) density of dipterocarp seedlings of commercial timber trees produced in 1991 at the three forest areas. Error bars indicate \pm 1 SE. Demographic calculations are based only on a matched subsample of forest transects across the experimental planting areas. Gunung Palung National Park (GP) represents a sample of 120 trees of 21 dipterocarp species found in the sandstone forest formation. The Sungai Matan (SM) logged area sample contained 206 trees and stumps of 18 dipterocarp species. The Sungai Matan control (SM-CON) represents an unlogged area or "control" within the SM concession, where 53 trees from eight dipterocarp species were monitored. Viable seed counts represented all undamaged seeds obtained in $101-\mathrm{m}^{2}$ plots within each transect (GP, $n=170$; SM, $n=160$; and SM-CON, $n$ $=50$ plots). GP samples contained 5387 seedlings, the unlogged control (SM-CON) contained 3233 seedlings, and the SM logged sample included 1905 seedlings, all established in the 1991 mast event.

sect discovered by pigs in the two separate mountain valley complexes (two-way ANOVA: $F_{1,12}=0.189, P$ $=0.6712)$. Ten clumps $(7.2 \%)$ from seven transects at the logged site were not attacked before all seedlings germinated. At GP, 47 clumps (29.6\%) from 16 transects germinated before any vertebrates arrived at the clump.

Ridge-top transects located on or near pig migration routes all exhibited significantly more predation than did slope-transversing transects (Fig. 3a; ANOVA: $F_{1,14}$ $=16.839, P=0.0011)$. Transects that traverse slopes also were located on wet or damp sites (stream crossings occurred on slope-transverse transects; Fig. 3a; $P$ $=0.0164$, Scheffé $S$ ). In addition, some seedlings were trampled by pigs when other experimentally sown seeds were eaten, indicating that they encountered the
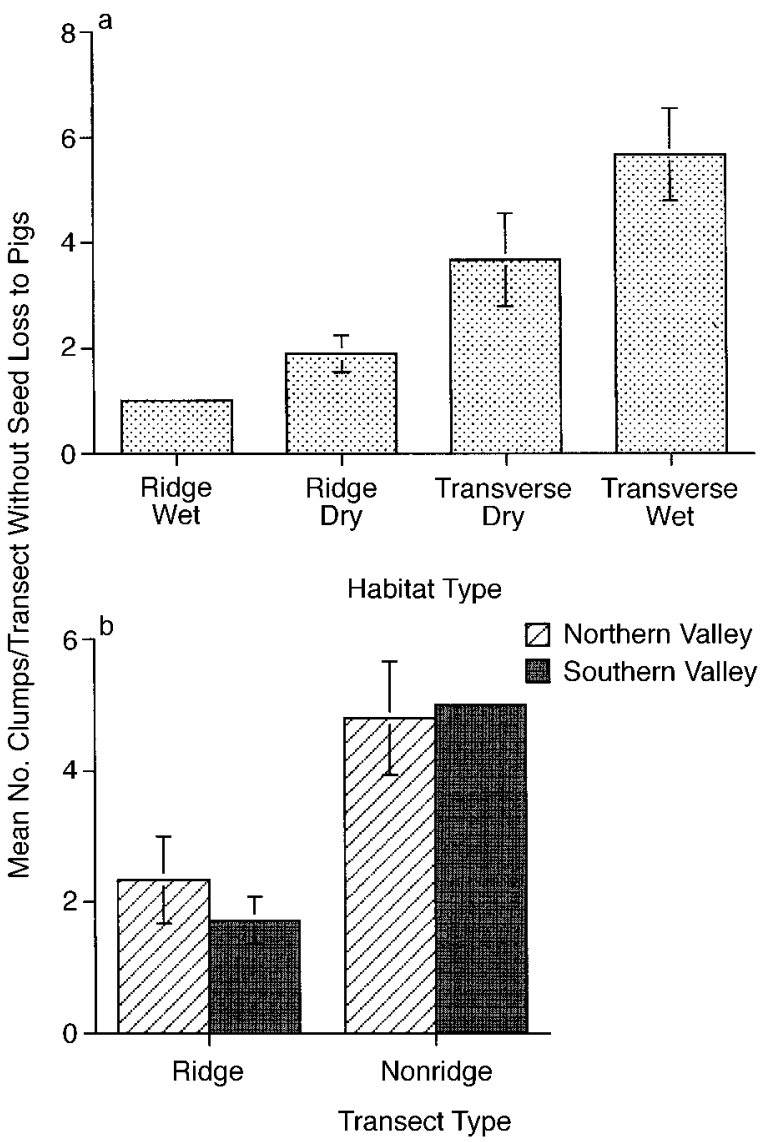

FIG. 3. Mean ( $\pm 1 \mathrm{SE}$ ) number of clumps per transect escaping seed predation by bearded pigs at Gunung Palung National Park by (a) transect site condition and (b) mountain valley complex. (a) Transects that traverse forest ridges had significantly greater numbers of clumps missed by pigs than did transects on ridges (ANOVA: $F_{(1,14)}=16.839, P=$ $0.0011)$. Wet sites also displayed significantly more intact clumps than did dry sites $(P=0.016$, Scheffé $S)$. (b) Mountain valley complexes did not display any significant differences in the mean number of clumps attacked by bearded pigs when the type of transect was factored out of the comparison (ANOVA: $\left.F_{1,12}=0.101, P=0.7564\right)$.

clumps after some seeds had germinated. There was no major effect of the mountain valley system in the distribution of pig seed attacks when the type of transect (ridge-top, slope-traversing) was factored into the comparison (Fig. 3b; two-factor ANOVA: $F_{1,12}=0.101, P$ $=0.7564)$.

Spatial autocorrelation of vertebrate seed predation.-Within transects, patterns of predation indicated the independence of seed clumps. The variance-tomean ratio among clumps was $\sim 1.0$. Among transects, the variance-to-mean ratio at each site varied from 0.61 to 3.00 but was generally $>1.0$ (Table 1 ), and transects were pooled for each site (GP site, $\bar{X}=3.48$; SM site, $\bar{X}=10.98$ ). There was no discernible pattern for grouping of pig attacks in meta-analyses, across the primary forest $\left(\chi^{2}=29.35\right.$, df $\left.=32, P>0.7\right)$. Spatial auto- 
TABle 1. Spatial analyses for the GP (Gunung Palung National Park) experimentally sown seed. Columns 2-5 display the variance-to-mean ratios for selected types of seed and seedling mortality in each transect and summed across the GP site.

\begin{tabular}{|c|c|c|c|c|c|}
\hline Transect & $\begin{array}{l}\text { Pig seed } \\
\text { predation }\end{array}$ & $\begin{array}{l}\text { Verte- } \\
\text { brate } \\
\text { herbi- } \\
\text { vory }\end{array}$ & $\begin{array}{l}\text { Seed- } \\
\text { ling } \\
\text { mor- } \\
\text { tality, } \\
\text { 2nd } \\
\text { census }\end{array}$ & $\begin{array}{c}\text { Seed- } \\
\text { ling } \\
\text { mor- } \\
\text { tality, } \\
\text { 3rd } \\
\text { census }\end{array}$ & $\begin{array}{l}\text { Probability } \\
\text { of pig } \\
\text { attack on } \\
\text { seed clump }\end{array}$ \\
\hline 1 & 2.42 & 0.00 & 1.89 & 2.01 & 0.26 \\
\hline 2 & 0.74 & 0.95 & 0.97 & 1.21 & 1.00 \\
\hline 3 & 2.20 & 2.30 & 1.52 & 2.31 & 0.74 \\
\hline 4 & 0.76 & 2.32 & 0.80 & 0.00 & 1.00 \\
\hline 5 & 0.78 & 0.00 & 0.60 & 0.42 & 1.00 \\
\hline 6 & 0.61 & 0.00 & 2.10 & 1.80 & 0.20 \\
\hline 7 & 1.48 & 1.07 & 1.54 & 2.00 & 0.03 \\
\hline 8 & 1.07 & 0.00 & 1.35 & 1.19 & 1.00 \\
\hline 9 & 0.73 & 0.90 & 2.01 & 1.73 & 1.00 \\
\hline 10 & 1.70 & 1.70 & 1.35 & 2.26 & 0.26 \\
\hline 11 & 3.00 & 2.40 & 1.78 & 1.73 & 0.33 \\
\hline 12 & 1.54 & 0.99 & 1.66 & 2.63 & 0.83 \\
\hline 13 & 2.81 & 1.70 & 0.96 & 0.00 & 0.53 \\
\hline 14 & 1.25 & 1.20 & 0.93 & 1.21 & 0.53 \\
\hline 15 & 1.94 & 1.10 & 1.16 & 1.52 & 0.33 \\
\hline 16 & 1.81 & 2.33 & 1.24 & 0.00 & 0.05 \\
\hline Mean, GP & 3.48 & 3.06 & 2.85 & 3.06 & \\
\hline Mean, SM & 10.98 & 4.97 & 3.75 & 3.80 & \\
\hline
\end{tabular}

Note: Summary statistics for similar analyses within the logged SM forest (Sungai Matan) are shown below the GP values.

$\dagger$ Bearded pig attacks on seed clumps are treated as a binomial variable (seed mortality or no mortality), and runs analyses are performed for each transect within GP. The probability of a seed clump being preyed upon by pigs in each transect is shown $\left(\chi^{2}=29.35, \mathrm{df}=32, P>0.6\right)$.

correlation variograms of pig attacks on clumps are presented in Fig. 4a; clumping of mortality was not detected at any scale at either site. The lack of any clustering was readily apparent in the logged forest, which had only 10 of 138 clumps undetected. The logged site suffered much greater bearded pig predation on seeds than did the primary forest. The number of clumps attacked $(P<0.001)$ and the mean number of clumps attacked per transect $(P<0.001)$ were both significantly greater in SM than in GP (Fig. 5).

Invertebrate seed predation.-At SM, all seeds that escaped vertebrate seed predation germinated and seed loss from postdispersal insect attack was not observed. In contrast, 37 or $4.8 \%$ of seeds at GP failed to germinate because of postdispersal insect (Scolytidae) attack. An additional $8.1 \%$ of the original seeds had germinated, but died from insect infestation and subsequent damage to the embryo. The primary forest site had significantly greater numbers of seeds destroyed by postdispersal insect seed predators $(12.9 \%)$ than did the logged forest (0\%; Fig. 5).

Overall site comparison.-The adjusted weekly mortality rate between the first and second census ( $6 \mathrm{wk}$ ) was 0.195 at GP and 0.284 at SM (Tables 2 and 3).
Thus, the logged site lost more of the experimentally sown seed than did the protected forest $(P<0.001)$. The total combined seed loss from both insects and vertebrates in the first and second censuses was significantly greater in the logged forest (SM) than in the protected forest GP (Fig. 5). Only 7.2\% of the SM clumps were intact, compared with $19.4 \%$ of GP clumps $(P<0.0001)$. The weekly mortality rate for GP (0.169) differed significantly from that for SM $(0.255)$ for the first $7 \mathrm{wk}(P<0.001)$.

A contrast of seedling survival in the "natural" mast community seed and seedlings with the experimentally sown seed reveals that the experimental population lost more than twice as many seeds and seedlings per week at either site compared with Shorea communities during the same sampling interval. Mortality rates at $7 \mathrm{wk}$ were: SM, 0.117; SM-Control, 0.115; and GP, 0.096 (Tables 2 and $3 ; P<0.001$ for greater mortality within the experimental seeds than in natural communities at both sites).

Herbivory.-Vertebrate herbivory was concentrated in the first 6-7 wk post-sowing. Vertebrates appeared to prefer young seedlings $<49 \mathrm{~cm}$ in height, browsing the apical meristems, the first pair(s) of young leaves, and sometimes the cotyledons. After this stage, seedlings apparently were unpalatable to vertebrate herbivores. New leaves produced by older seedlings did not display evidence of vertebrate herbivory in later censuses. The primary forest site had significantly higher levels of vertebrate herbivory than the logged forest (Fig. 5; $P<0.0001$ ). Experimental seedlings at GP averaged $12.5 \% \pm 1.3 \%$ leaf area $(\bar{X} \pm 1 \mathrm{SE})$ lost to insect herbivores (range 0-75\%). SM seedlings had significantly lower herbivory $(5.4 \% \pm 1.1 \%$; range: 0 $50 \%$ ) than did those at the GP protected site (ANOVA: $\left.F_{1,319}=13.273, P=0.0003\right)$.

\section{Third census}

Weekly mortality rates of experimental seed were similar for both forests: $\mathrm{GP}=0.056$ and $\mathrm{SM}=0.050$ ( $P=0.503)$. A contrast of survival of the "natural" mast seedlings with the experimentally sown seedlings reveals that the late $S$. stenoptera seedlings lost a similar percentage of seedlings at SM but not at GP (SM Shorea community, $0.055 \%, P=0.399$; SM Control Shorea community, $0.043 \%, P=0.133$; GP Shorea community, $0.043 \%, P=0.042)$. Within each site, the correlograms showed no spatial autocorrelation in seedling mortality (Fig. 4b; GP, $\chi^{2}=14.75$, df $=32$, $P>0.99$; SM, $\chi^{2}=8.64$, df $=20, P>0.98$; transects without seedlings were excluded). Thus, there was no detectable pattern in seedling deaths between the second and third census. No significant differences between sites in seedling height (GP, $64.5 \pm 1.2 \mathrm{~cm}$; SM, $60.7 \pm 1.6 \mathrm{~cm}$ ) or percentage of insect herbivory (GP, $7.8 \% \pm 1.0 \%$; range: $0-50 \% ; \mathrm{SM}, 6.9 \% \pm 1.1 \%$; range $0-50 \%$ ) were found between sites (values are expressed as $\bar{X} \pm 1 \mathrm{SE})$. Survivorship was significantly related to 
a) Bearded Pig Predation of Clumps

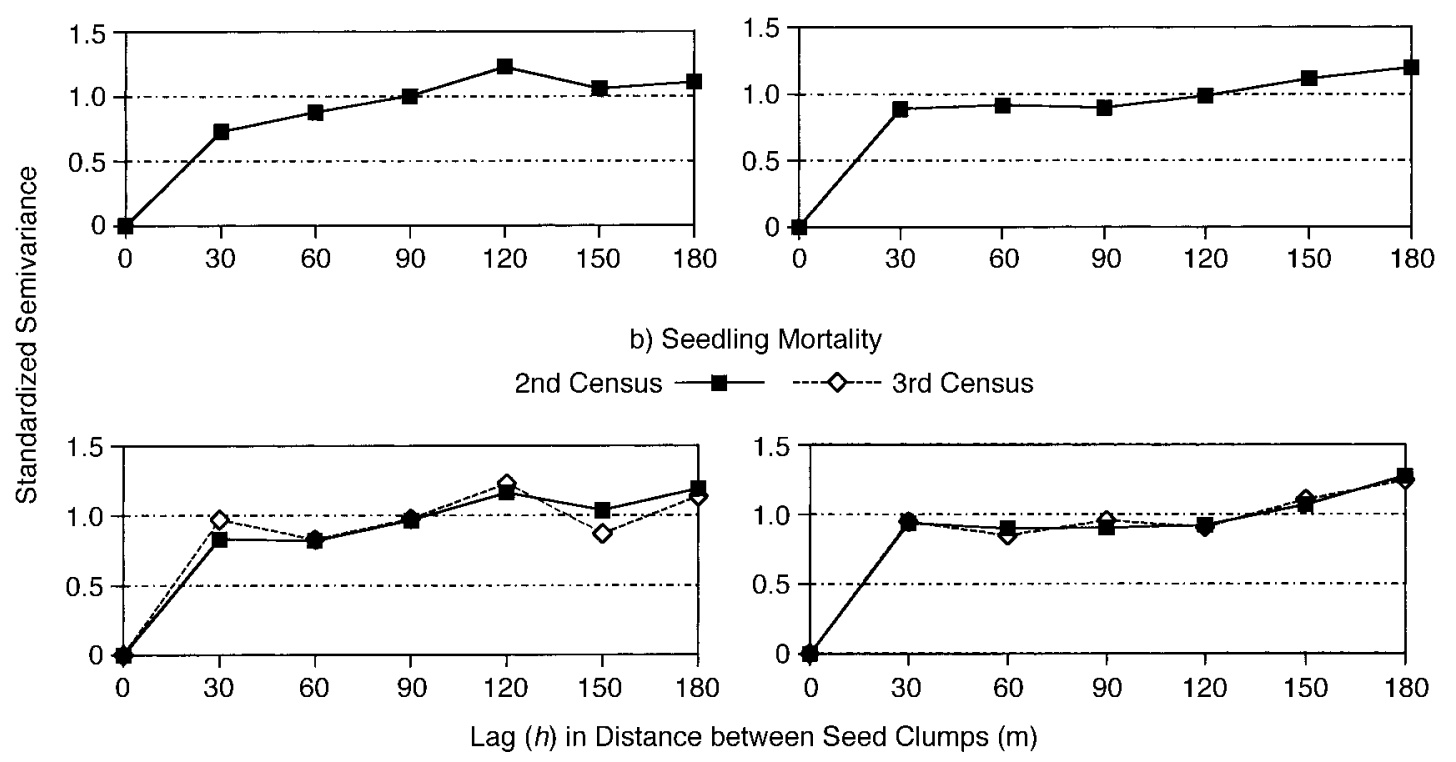

FIG. 4. Spatial autocorrelation of seed and seedling mortality of the experimental populations at both sites for (a) the number of seeds eaten by pigs and (b) seedling death in the second census ( 7 wk post-sowing) and third census (14 wk post-sowing). All transects were combined to calculate the spatial association from $30-\mathrm{m}$ to $180-\mathrm{m}$ clump separation distances. Each plotted point represents the mean of all transects. Lag $(h)$ is the distance $X$ (in meters) over which the semivariance is measured. The shape of the semivariogram is such that $X$ increases with $h$ until it reaches maximum or sill. The lag at which the sill is reached is the range. The range is a measure of spatial dependency or homogeneity, whereas the sill reflects the amount of spatial variablity.

the combined independent variables of height, leaf number, and herbivory levels measured on seedlings during the second census from both sites (MANOVA: Wilks' Lambda $\left.=0.866 ; F_{1,319}=16.338, P<0.0001\right)$.

\section{Fourth census}

Mortality rates approximately doubled (0.097 at GP, 0.079 at SM) for $S$. stenoptera seedlings between the third and fourth censuses, compared with the previous census interval. These mortality rates were similar at the two sites $(P=0.203)$. During the same period, however, $S$. stenoptera experienced significantly greater mortality than did the mast-fruiting Shorea community at either site (Tables 2 and $3 ; P<0.001$ ). Shorea pinanga, for example, had a very low weekly mortality rate of only 0.018 in newly germinated seedlings $(P<0.001)$.

Herbivory levels and S. stenoptera seedling height in the third census were not significantly related to survival in the fourth census at either site (herbivory, $F_{1,229}=0.052, P=0.8197$; height, $F_{1,229}=0.466, P$ $=0.4957$ ). Over $53 \%$ of the seedlings at GP surviving at the fourth census had apical meristem damage. At GP, seedlings had a mean height of $82.8 \pm 4.6 \mathrm{~cm}$ and average herbivory levels of $4.3 \% \pm 1.6 \%$. SM seedlings, on average, were smaller $(65.3 \pm 4.0 \mathrm{~cm})$ and had slightly greater leaf loss to insect herbivores $(7.3 \%$ $\pm 2.3 \%$ ) than did GP seedlings. Only the number of leaves in the third census was significantly related to seedling survival through the drought at both sites $\left(F_{1,229}=10.326, P=0.0015\right)$. Despite the drought, there was no significant pattern of S. stenoptera seedling deaths at either site in meta-analyses applied to the number of clumps that lost seedlings between the third and fourth census (Fig. 4b; GP, $\chi^{2}=25.57$, df $=$ 28, $P>0.7$; SM, $\chi^{2}=9.19$, df $\left.=22, P>0.98\right)$.

\section{Fifth census}

At GP in March 1994, 65.2\% of S. stenoptera seedlings (15 of 23) survived from the fourth census, with some having attained a height exceeding $2.5 \mathrm{~m}$ (135.6 $\pm 14.5 \mathrm{~cm})$. Weekly mortality between the fourth and fifth census (126 wk) thus was low (0.004). Seedling survival was not found to be influenced by forest conditions at GP. Although samples sizes were small, 53\% of seedlings in the shaded understory died between the fourth and fifth census compared with $20 \%$ of the seedlings found in or near forest gaps $(P=0.107 ; 1000$ randomizations). Seedlings established in gaps or edges of gaps attained greater height than seedlings in the forest understory (gap, $166.4 \pm 17.2 \mathrm{~cm}$; understory $89.3 \pm 6.8 \mathrm{~cm}$; ANOVA: $\left.F_{1,14}=12.23, P=0.0039\right)$. Seedlings associated with light gaps also had more leaves than understory seedlings (gap, $17.1 \pm 3.4$ 


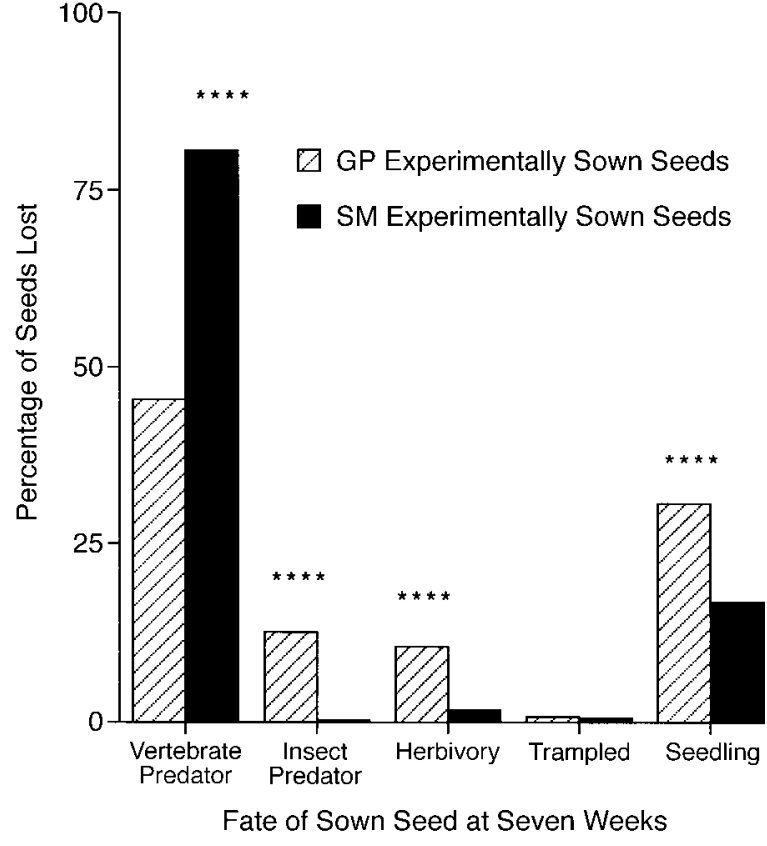

FIG. 5. An across-site or seed density comparison of the relative percentage of seeds and seedlings lost to different sources of mortality for experimentally sown (Shorea stenoptera) populations. Seeds that escaped mortality and established are included in the category "Seedling." Results are presented for the second census (7 wk post-sowing). Randomization tests were applied to the number of clumps hit Significantly greater loss is indicated by asterisks $(* * * * P<$ 0.0001). The GP National Park sample shown is 795 seeds or seedlings, and the SM logged site sample shown is 690 seeds or seedlings.

leaves; understory, $6.7 \pm 1.6$ leaves; ANOVA: $F_{1,14}=$ $6.092, P=0.0282$ ). The forest light categories (gap or understory) were not significantly related to the percentage of seedling leaves exhibiting $>50 \%$ herbivory (gap, 58.4\% $\pm 5.7 \%$; understory, $64.3 \% \pm 10.5 \%$; ANOVA: $\left.F_{1,13}=0.499, P=0.4926\right)$.

\section{Overall survival patterns}

The overall mean weekly mortality rate for the two experimental populations calculated across the 34-wk period was significantly different $(P<0.001)$ between logged and primary forest sites $(\langle\lambda\rangle \pm 1 \mathrm{SD} ; \mathrm{SM}, 0.227$ \pm 0.067; GP, $0.144 \pm 0.041$; Tables 2 and 3). Fig. 6 contrasts the relative percentage of loss of experimentally sown seed and seedlings by agent for each forest area. For the entire 40-mo period at GP, weekly mortality rate for experimentally sown seeds was only 0.025 . The percentage of seedlings surviving to each census (7-34 wk) is presented for both experimental populations in Fig. 7.

\section{Community seed predation levels of natural mast-fruiting species}

Vertebrate predation was low in the "natural" mastfruiting dipterocarp community in relation to the amount and mass of seed produced by these trees at both sites. At GP, only 18 seeds $(0.3 \%)$ from a sample containing 5174 mature-ripe seeds of 21 species were destroyed by arboreal or terrestrial vertebrates. Although seed predation at SM was higher than at GP, only 208 seeds $(11.8 \%)$ were attacked by vertebrate predators from the total sample of 1768 mature-ripe seeds across all 21 dipterocarp species. A each site, the experimentally sown population lost significantly more seed to predators than did the entire mast-fruiting dipterocarp community. The GP dipterocarp community lost an average of $470 \pm 260 \mathrm{seeds} / \mathrm{ha}$ or $1.08 \pm 0.54$ $\mathrm{kg}$ dry mass/ha $\bar{X} \pm 1 \mathrm{sE}$. This was only $0.74 \%$ of the forest's total output mass. In contrast, the GP experimentally sown population lost $58 \%$ of its seeds to predators. At GP, $7 \mathrm{~kg} / \mathrm{ha}$ of experimentally sown seed were destroyed by terrestrial predators, compared with 1.08 $\mathrm{kg} / \mathrm{ha}$ of seed for the entire mast-fruiting community. Similarly, natural dipterocarp species at the SM logged site lost $7190 \pm 2720$ seeds/ha or dry mass of $5.19 \pm$ $2.28 \mathrm{~kg} / \mathrm{ha}$. This represents $15.4 \%$ of the total forest seed production mass. At SM, 80.9\% (7.05 kg/ha) of the experimentally sown seed was lost.

The experimental population lost seed from significantly more clumps and transects than did the natural dipterocarp community. At GP, $70 \%$ of the S. stenoptera clumps from $100 \%$ of the transects exhibited vertebrate seed predation, whereas only $4.1 \%$ (7 of 170) of the GP plots from $23.5 \%$ of the transects experienced any vertebrate seed predation (by clumps vs. plots, $P$ $<0.0001$; by transects, $P=0.0001)$. Similiarly, at SM, $93 \%$ of the clumps from $100 \%$ of the transects lost

TABLE 2. Mortality rates of seeds and seedlings through the 34-wk sampling period.

\begin{tabular}{lrrccc}
\hline \hline & & \multicolumn{3}{c}{ Interval } \\
\cline { 3 - 4 } \multicolumn{1}{c}{ Site } & $N$ & $7 \mathrm{wk}$ & $14 \mathrm{wk}$ & $34 \mathrm{wk}$ & $\lambda \pm 1 \mathrm{sD}$ \\
\hline GP experimental & 795 & 0.169 & 0.056 & 0.097 & $0.144 \pm 0.041$ \\
GP natural Shorea spp. & 2964 & 0.096 & 0.043 & 0.031 & $0.072 \pm 0.030$ \\
GP S. pinanga & 39 & 0.047 & 0.048 & 0.018 & $0.040 \pm 0.014$ \\
SM experimental & 690 & 0.255 & 0.050 & 0.079 & $0.227 \pm 0.067$ \\
SM natural Shorea spp. & 446 & 0.115 & 0.055 & 0.067 & $0.093 \pm 0.026$ \\
SM-CON natural Shorea spp. & 966 & 0.117 & 0.043 & 0.045 & $0.091 \pm 0.035$ \\
Total monitored & 5900 & & & &
\end{tabular}

Note: The instantaneous mortality rates for the three intervals are shown with the initial sample size and the mean rate adjusted for the sampling interval. 
TABLE 3. Mortality from intervals contrasted with mortality expectations based on the overall mean rate $\langle\lambda\rangle$ expected in each of the intervals.

\begin{tabular}{lccc}
\hline \hline \multicolumn{1}{c}{ Site } & $0-7 \mathrm{wk}$ & $7-14 \mathrm{wk}$ & $14-34 \mathrm{wk}$ \\
& $P(>$ expected $)$ & $P(<$ expected $)$ & $P(>$ expected $)$ \\
\hline GP experimental & $<0.001$ & $<0.001$ & 0.002 \\
GP natural Shorea spp. & $<0.001$ & $<0.001$ & $<0.001$ \\
GP S. pinanga & 0.784 & 0.776 & 0.026 \\
SM experimental & 0.009 & $<0.001$ & $<0.001$ \\
SM natural Shorea spp. & 0.006 & 0.006 & 0.036 \\
SM-CON natural Shorea spp. & $<0.001$ & $<0.001$ & $<0.001$ \\
\hline
\end{tabular}

Notes: $P$ values were determined from 1000 Monte Carlo simulations. Note that the second interval is less than expected, whereas the first and third intervals are greater than expected.

experimentally sown seed to vertebrates, whereas only $15 \%$ of the natural dipterocarp community in SM plots (50\% of the transects) lost any seeds to vertebrates (by clumps vs. plots, $P<0.0001$; by transects, $P=$ $0.0014)$.

A within-site comparison of cause of mortality at GP revealed that the experimental population differed significantly from the natural Shorea community in terms of the relative percentage of seeds and seedlings lost (Figs. 6 and 7). The experimental population suffered significantly greater seed loss to vertebrate seed predators than did the natural Shorea community $(P<$ 0.0001). The natural Shorea community established significantly more seedlings $(P<0.0001)$, despite

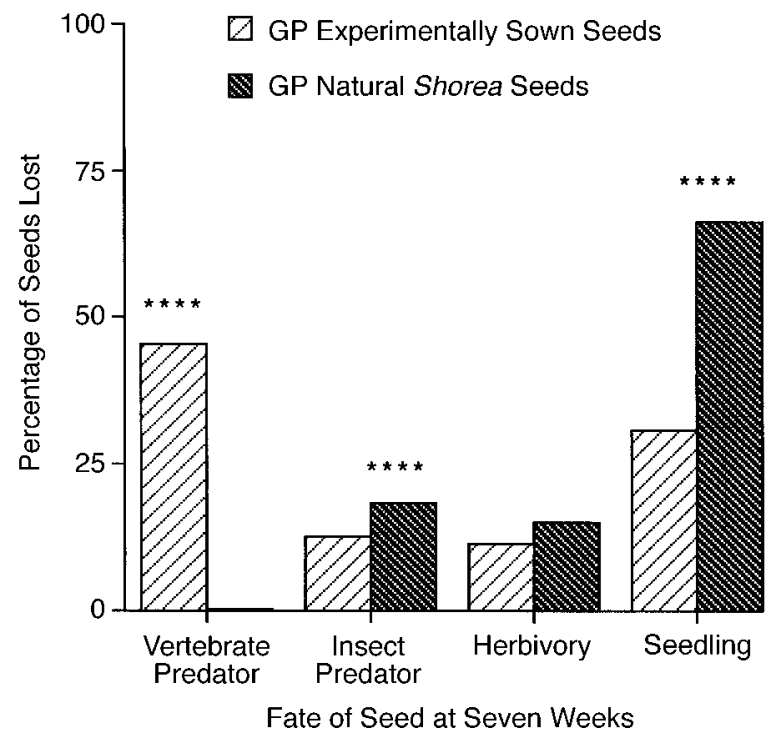

FIG. 6. A within-site or temporal comparison of the relative percentage of seeds and seedling lost to different sources of mortality in the GP experimental population vs. the GP mast-fruiting Shorea community. Seeds that escaped mortality and became established are included in the category "Seedling." Randomization tests were applied to clumps and transects. Significantly greater loss is indicated by asterisks (**** $P<0.0001$ ). The GP experimentally sown population consists of 795 seeds, whereas the naturally dispersed masting GP community includes 15 Shorea spp. for a sample of 2964 individuals. greater seed and seedling losses to insects $(P<$ $0.0001)$, than did the experimentally sown population.

Late-fruiting Shorea species.-Peak Shorea gratissima (Wall, ex Kurz) Dyer fruit fall at GP occurred 2 wk later than the peak for otherwise synchronous naturally occurring dipterocarps. Similarly, peak fruit fall for S. laevis Ridl. lagged $1 \mathrm{wk}$ at SM. Both of these late-fruiting species at each forest site accounted for the majority of dipterocarp seeds lost to vertebrate seed predators. Shorea gratissima suffered $44.4 \%$ of the vertebrate seed predation recorded in the entire GP dipterocarp community. Similarily, at SM, S. laevis accounted for 44.7\% (93 of 208) seeds of 21 species destroyed by vertebrate predators in the logged forest. In the unlogged SM control in the timber concession, $89.2 \%$ (470 of 527) of the seeds destroyed by vertebrates were $S$. laevis. At both sites, the remaining seed loss was distributed across many dipterocarp species. Not only is vertebrate seed predation extremely low in both dipterocarp forest communities, but also the great majority of seed loss is concentrated in the late-fruiting species at each site.

In the unharvested control forest, reproductive individuals of $S$. laevis ( $>49 \mathrm{~cm} \mathrm{dbh}$ ) were found at mean densities of 6.5 trees/ha $\left(4.69 \mathrm{~m}^{2} / \mathrm{ha}\right)$ or $55.4 \%$ of the reproductive Shorea community basal area. Over the $1-\mathrm{km}^{2}$ logged area, $S$. laevis densities were reduced directly by timber harvest and indirectly by logging damage to $1.3 \pm 0.34$ reproductive trees or $0.73 \pm 0.21$ $\mathrm{m}^{2} /$ ha. Despite the changes in density and dominance, $S$. laevis seeds were heavily attacked by predators at both sites.

\section{DISCUSSION}

The pattern of vertebrate seed predation was a result of the timing of germination coupled with the timing of predator arrival. Rather than swamping predators at only a single location (Silvertown 1980), dipterocarps rely on seed escape both in time and in space (Janzen $1971 b$ ). Rather than having clumps missed by predators, allowing seeds time to germinate, successful seeds germinated earlier, thus limiting exposure to seed-eating vertebrates. Many of the clumps discovered by pigs lost only a portion of the seeds because most had ger- 

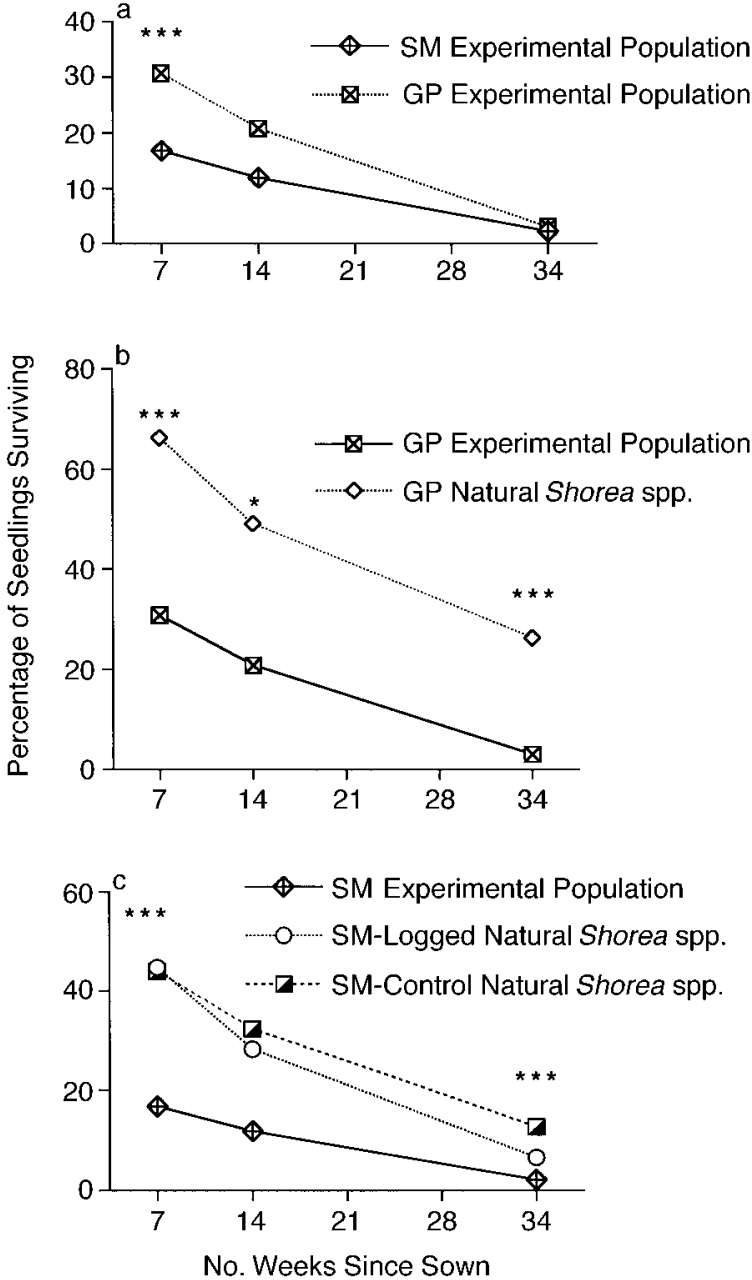

FIG. 7. Percentage of seedlings surviving to each census date for (a) the experimentally sown populations across sites, (b) the experimentally sown and mast-fruiting Shorea populations within the GP site, and (c) within the SM site. The GP experimentally sown sample contains 244 seedlings, and the SM experimentally sown sample contains 116 seedlings. The GP experiment is compared to 15 Shorea $\mathrm{spp} .(n=1517)$ The SM experiment is compared to 15 Shorea spp. $(n=966$ for SM-CON and $n=446$ for SM). Both the experimentally sown and the mast communities at SM were destroyed by logging at $50 \mathrm{wk}$ post-planting. Randomizations were run on the weekly mortality rate for each interval against the mean mortality rate of the population, following Sheil and May (1996), but percentages are plotted. At $7 \mathrm{wk}$, the GP experimentally sown population differed significantly $(P<0.001)$ from the SM experimentally sown population, but at 14 wk $(P=0.501)$ and $34 \mathrm{wk}(P=0.203)$, the two experimentally sown populations did not differ in mortality rates. The GP experiment differs significantly from the natural Shorea population at 7,14 , and $34 \mathrm{wk}(P<0.001, P=0.042$, and $P<$ 0.001 , respectively). At SM, the experimentally sown population was significantly different from the natural Shorea populations at both the logged and control sites at $7 \mathrm{wk}(P$ $<0.001)$ and at the control site in week $34(P=0.004)$, but did not differ from the SM populations at week $14(P=0.622)$ or week $34(P=0.307)$ for the logged site. The SM-logged and SM-control natural Shorea populations did not differ significantly in week $7(P=0.788)$ or week $14(P=0.133)$ but did differ in week $34(P=0.004)$. minated. Second, all transects in each forest experienced bearded pig attack. Shorea seeds germinate within $2 \mathrm{wk}$ of dispersing. With little predation after the first week of planting, seeds are expected to germinate within the following week. The first sighting of migrating bearded pigs occurred in the mountains on 9 April at the Gunung Palung site, $10 \mathrm{~d}$ post-planting. Pigs, therefore, had only a few days to eat before all seeds had germinated. The spatial pattern of attack corroborates this scenario. If experimentally sown seeds had been planted 2 wk earlier, all Shorea stenoptera seed would have germinated and, thus, none would have been available for nomadic pigs. Dipterocarp seeds avoid predation by escaping in time through concurrent fruit fall with rapid germination. Moreover, greater seed predation in the logged forest than in the protected site was correlated with differential movement times of predators. Bearded pigs moved into the sampled site in the logged forest earlier than in the protected forest. If $S$. stenoptera seeds had been distributed $2 \mathrm{wk}$ after the mast fruiting (when bearded pigs had arrived at both sites), it is unlikely that any seed would have escaped predation at either site.

Both experimentally sown and "natural" dipterocarp seeds that were dispersed at the tail of a major mastfruiting event had a highly reduced probability of survival compared with seeds dispersed at the peak fruit fall. With low regional seed production, the logged forest lost a significantly greater percentage of seed to predators in both the natural and the experimentally sown seed cohorts than did the protected forest. However, this was not a purely local site or seed density effect. Terrestrial seed-eating vertebrates were not present and swamped by copious seed throughout the mast; they were absent from the protected area longer than from the logged site. This allowed more seed to escape by rapid germination as nomadic predators were swamped by dipterocarp seed across the entire region (Curran and Leighton 2000).

This study demonstrates that the numerical increase of vertebrates (through both local movement and population recruitment) exerts the selective pressure necessary to select for concurrent fruit fall across large forest regions. On every sampled transect within the sampled areas $\left(\geq 1 \mathrm{~km}^{2}\right)$, vertebrate seed predation resulted in substantial seed losses in S. stenoptera. If predators were swamped with copious seed only on a local scale (e.g., within 1-50 ha), either total seed destruction, or at least much higher levels of seed predation, would have occurred. Few, if any, seeds should have escaped predation at the logged forest where seed production (in kilograms) was only $23 \%$ of the protected site production. Rather than local seed escape, the per capita predation rate depends on the ratio of prey (dipterocarp seed) to seed predators (primarily bearded pigs). This pattern conforms to the theory of ratio-dependent predation, which operates by a spatial aggregation of predators relative to prey distribution 
and reflects different spatial scales of foraging and population dynamics (Hanski 1991).

Seed escape, however, was evident in the first census, when dipterocarp seed was still available in the region. In the experimental populations, 92\% (from SM) and 99\% (from GP) of the sown seed remained undamaged. The lack of seed predation in the first week is remarkable, particularly when compared with seed predation percentages in other large-seeded, tropical canopy trees in nonmasting forest communities (i.e., $>75 \%$ lost in 2 wk; Howe et al. 1985, Howe 1990). If seedfall is concurrent with seed production by other dipterocarp populations across a large forested area, seeds have a high probability of escape. Thus, the temporal pattern of fruit fall is critical for seed survival.

Given the potential decision rules of foraging pigs across a landscape, arrival time differences probably were a consequence of regional food resources having been reduced elsewhere and, thus, exhausted earlier in the logged sites than were seed resources in undisturbed forests surrounding the GP site. Experimentally sown seeds could not have attracted the nomadic vertebrates, because the seeds were unknown to the predators before their arrival and, thus, could not effect the number of individuals recruiting to the area. The experimentally sown seeds may have influenced pigs' ranging decisions (e.g., to remain rather than disperse), but added only $0.32-0.33 \mathrm{~kg} / \mathrm{ha}$ across each forest area. The additional sown seed represents a relative increase in the total dipterocarp seed production of only $0.22 \%$ at GP and $0.98 \%$ at SM (based on kilograms per hectare). Thus, the relatively small amount of added seed could not support these large-bodied vertebrates for long.

Synchrony of fruit fall over large spatial scales must allow some dipterocarp seed in some regions to escape predation. Coupled with their rapid germination, dipterocarp seeds thus can escape predation in time and space. This dual mechanism, "regional escape" (Curran 1994, Curran and Leighton 2000), may explain the puzzling lack of seed predation observed by Medway (1972) and McClure (1966) during mast-fruiting events in Peninsular Malaysia. Bearded pigs are solitary, scattered individuals during the long intermast intervals. Group formation and seasonal migrations begin during dipterocarp mast-fruiting events (Pfeffer 1959, Caldecott and Caldecott 1985, Curran 1994, Curran and Leighton 2000). Over 800000 pigs were observed migrating out of Northeast Kalimantan after the 1983 dipterocarp mast event and severe El Niño-associated drought, indicating that large populations still exist throughout Borneo (Caldecott and Caldecott 1985). Pig populations may have been depressed through lean years, and remained undetected in Medway's or McClure's 1-ha research areas. This provides an important clue as to stochastic forces that influence pig distribution, which, in turn, plays an important role in dipterocarp recruitment success. Although some pig migration or travel routes may be more likely to be used during mast events, the long intermast interval coupled with pig dispersal, suggests that chance may determine pig distribution when a mast event occurs. Thus, the interspecific regional mast-fruiting, coupled with rapid germination, is sufficient to ensure seedling regeneration in some, but not all, local sites in major mast events, even though it appears that vertebrates will consume all of the seed that they encounter.

Observations recorded during two previous mast events (1986 and 1987) in West Kalimantan corroborate this mechanism (Curran 1994). During the 1987 major mast event (which exhibited similar dipterocarp seed production as in 1991), dipterocarps in GP lost few seed to vertebrates. A 1986 minor mast-fruiting episode within the GP lowland forest displayed a qualitatively different pattern of seed predation by resident and nomadic vertebrates (Curran and Leighton 2000). In this minor mast, dipterocarp seed production was approximately equal to seed production at the SM logged site in 1991. Although large amounts of seed were produced, this "minor" mast occurred 6 mo outside of the regional peak. Tremendous numerical increases were observed in populations of a diversity of seed-eating vertebrates, with the result that all monitored seed was destroyed (Curran 1994, Curran and Leighton 2000). However, the majority of seed produced at the SM logged site in synchrony with the 1991 regional mast escaped seed predation in that year. This suggests that within-site production of seed per se is not the critical factor; rather, it is the spatiotemporal pattern of seed production, coupled with the distribution and abundance of predators across the landscape, that dictates the probability of local seed survival.

\section{Insect postdispersal seed predation}

Postdispersal insect seed predators destroyed significantly more seed in the protected forest (GP) than in the logged site (SM). The logged site did not lose any seed to insect seed predators. Bark beetles (Scolytidae: Coccotrypes spp.) can only destroy seeds that are not found immediately by bearded pigs. Although bark beetles can colonize a seed within a few days of planting, population recruitment levels that would either kill a seed or make it unsuitable for pig consumption would require much longer periods. Most experimentally sown and naturally dispersed dipterocarp seed germinated before insect infestations became lethal. In addition, insect seed predator populations at SM may have been depressed because logging reduced ground cover and seed densities in previous mast events (e.g., 1982-1983 and 1986-1987), thus disrupting several insect reproductive cycles and altering forest floor conditions. As previously noted, the timing of pig attacks on seed (earlier at SM and/or later at GP) also would have contributed to the lower levels of insect seed destruction observed at SM. 


\section{Effects of herbivory}

Vertebrate herbivory of dipterocarp seedlings is an important source of mortality in the initial $6 \mathrm{wk}$ after germination. A similar pattern was recorded by Howe et al. (1985) and Howe (1990) for Virola surinamensis seedlings at Barro Colorado Island, Panama. In our study, survival probabilities in the $7 \mathrm{wk}$ that followed (14 wk since germination) were affected by initial and successive herbivore attacks. Defoliation and meristem damage of young Shorea stenoptera seedlings by vertebrates may accentuate mortality induced by other factors (e.g., drought stress) by suppressing root development. Similar arguments were posed by Howe (1990) regarding Virola seedlings. Howe (1991) and Marquis (1984) reported long-term impacts of vertebrate herbivores on seedling survival in neotropical forests. Similar mechanisms may likewise affect seedling survivorship in West Kalimantan long after herbivore attack.

Seedlings of S. stenoptera at GP suffered greater herbivore damage than did SM seedlings. This probably was due to greater densities of vertebrate herbivores and to greater densities of seedlings at the protected forest site than at the logged forest. Logged forest conditions, such as dense underbrush and numerous treefall snags, are not preferred habitats for mammalian herbivore populations. Hunting pressure by loggers also may reduce herbivore densities within timber concessions.

Natural and experimentally sown populations of Shorea species suffered relatively low levels of generalized invertebrate herbivory (0-10\% of leaf surface area). Regeneration studies from other regions also show that similarly low insect herbivory levels are not likely to have a strong influence on survival or growth (Becker 1983, Clark and Clark 1985, de la Cruz and Dirzo 1987, Howe 1990). Indirect effects (e.g., susceptibility to drought stress, infection, or lowered competitive abilities), however, may be accentuated even by low insect herbivore loads, but have rarely been tested experimentally (Marquis 1984, Crawley and Pacala 1991).

\section{Effects of microsites}

Experimental plantings of Shorea stenoptera demonstrate that if a seed escapes predation and vertebrate herbivory within the first $7 \mathrm{wk}$, the seedling will establish. Availability of suitable germination sites, in either primary or logged forest, does not appear to limit seedling establishment, as the experimentally sown species did not display any differences in seedling establishment in relation to forest floor conditions. These S. stenoptera seeds possess a strong, large radicle that readily penetrates the leaf litter at the logged forest site, and the seeds contain sufficient reserves to grow above dense underbrush. Furthermore, mortality rates across natural seedling communities in the SM logged forest did not differ significantly from rates in the SM experimentally sown population during the 14- and 34wk establishment periods. This was not the case in the GP protected forest, however, where experimentally sown seeds suffered significantly greater mortality than natural seedling communities at all three census intervals $(7,14$, and $34 \mathrm{wk})$. Only $1.9 \%$ of the initial experimental seed at GP survived to 40 mo. Dipterocarp regeneration appears to first be seed limited rather than microsite limited (Andersen 1989, Eriksson and Ehrlen 1992). Because seeds were placed systematically and evenly throughout the forest, we could determine that survivorship of large saplings (160 wk) was not significantly associated with broad forest light categories.

\section{Effects of a strong regional drought}

The 1991 El Niño-Southern Oscillation (ENSO) created the region's most extreme drought conditions since the 1982-1983 ENSO event, and the greatest drought of the century (until 1997-1988 ENSO; Leighton and Wirawan 1986, Salafsky 1994). The ENSO-associated drought conditions were correlated with significant seedling mortality at both sites, but with no discernible spatial pattern of seedling loss. Shorea stenoptera seedlings suffered significantly greater drought-related mortality compared with the rates of the "natural" Shorea community at both sites. An even more pronounced survival differential was found when S. stenoptera mortality rates were compared to mortality rates of its closely related congener at the site, S. pinanga. It is possible that $S$. stenoptera seedlings could have lower tolerance to drought stress than seedlings of other dipterocarp species in this region. Shorea stenoptera seedlings were planted in an area without conspecific adults. All naturally occurring dipterocarp seedlings should have acquired ectomycorrhizal infections by 3 mo (Alexander et al. 1992). These mycorrhizae are believed to confer an advantage in acquiring nutrients and moisture, both of which are especially critical during drought periods (Alexander 1989). Without some preexisting mycorrhizae associations with conspecific adults, S. stenoptera seedlings may have experienced difficulties in acquiring resources during the drought.

\section{Effects of dipterocarp timber extraction}

Although vertebrate seed predators destroyed much of the seed within the logged forest, their destruction of seeds is somewhat offset by the extreme reduction of postdispersal insects and vertebrate herbivores. Alterations in forest conditions, such as increased heat of the forest floor, or increased understory brush and treefalls, may result in greater habitat shifts of invertebrate and vertebrate predators and herbivores, respectively. Although the primary factors responsible for the population changes are unknown, commercial timber extraction of canopy dipterocarp trees resulted in at least a temporary loss of diversity in the invertebrate and vertebrate populations that feed on dipterocarp seed and seedlings. Results show that the logged forest ei- 
ther had a regional loss or severely depressed populations of postdispersal insect seed predators and vertebrate seedling herbivores during this experiment. It is unclear, however, whether primary (dipterocarp) or secondary (nondipterocarp) food resources or other factors were directly responsible for the reduced attacks.

\section{Implications for dipterocarp recruitment}

In this dipterocarp mast-fruiting system, a delay in the timing of seedfall after the community fruit fall peak is negatively correlated with two major components of plant fitness: seed survival and seedling establishment. Postdispersal seed predators may impose directional and/or stabilizing selection for the maintenance of extremely low variance in the timing of fruit fall observed in sympatric dipterocarp populations. Historically, foraging behavior by seed predators may have reduced variation to the present level. Dipterocarp trees are long-lived; therefore, differences in lifetime reproductive success cannot be measured directly. The observed quantitative differences in seed survival and seedling establishment between individuals that participate in the community mast-fruiting event and those that fruit outside the peak fruit fall period would, at the levels observed here, readily translate into differences in reproductive adults arising from those seeds or seedlings. This study demonstrates that the effect of generalist dipterocarp seed predators is strong enough to have influenced fruiting synchrony and dipterocarp seedling recruitment.

For dipterocarps, seed survival is positively, rather than negatively, density dependent. In this study, the number of seeds surviving did not increase with species density per se, but rather with regional densities of the dipterocarp community or total seedfall across a relatively large area. Because there were no reproductive adults of Shorea stenoptera at either site, we could not determine seed and seedling survival of S. stenoptera near reproductive individuals. Although forest patches with a high density of seeds beneath a fruiting tree may differentially attract seed predators, the mast-fruiting Shorea species investigated here did not experience any vertebrate predation oriented on the scale of an individual tree's seed shadow (Curran 1994). Regardless of adult density and dispersion, the majority of dipterocarp species dispersing seeds during the peak fruit fall period totally escaped seed destruction by vertebrates. In contrast, the rare, clustered, but late-fruiting S. gratissima suffered concentrated attack in and around the tree crown and seedfall area.

The late-fruiting Shorea laevis within the SM production forest provides an unusual test of the effects of local density and dispersion of reproductive individuals on vertebrate seed predation patterns. Timber extraction drastically altered the density and dispersion of S. laevis. Although it was the most dominant Shorea species in the unlogged control site, S. laevis became relatively rare and patchy through harvesting of adults in the logged forest. Despite changes in local density, dispersion, and dominance in the logged and control areas, $S$. laevis seeds were heavily attacked by predators at both sites. Again, this was correlated with the timing of fruit fall relative to other species in the region, rather than the density or distribution of reproductive individuals of $S$. laevis. Seed from both the common and the rare synchronously fruiting populations in the logged area escaped vertebrate seed predators with equal probabilities.

Unlike the well-known cases of reproductive synchrony in periodic cicadas and mayflies, which satiate resident predators locally (Lloyd and Dybas 1966, Karban 1982, Sweeney and Vannote 1982, Williams et al. 1993), dipterocarp communities must cope with largebodied, highly mobile generalist predators that move to areas with relatively high densities of seed. In this study, bearded pig predation of seeds was not uniformly distributed over the relatively large areas sampled at each site. If pigs happen to be in a particular area when a masting event arrives, they presumably remain in these patches until the rate of yield is reduced to the average food supply in the region. This foraging behavior conforms to predictions generated by Charnov's (1976) marginal value theorem. As individuals deplete their local resources, they move to areas that retain proportionally higher seed supplies. These seed predators tend to congregate in patches with the highest resource availability (Janzen 1976, Ims 1990). Herds begin to form and move across well-established access routes (Pfeffer 1959, Caldecott and Caldecott 1985, Curran 1994). This predator mobility introduces a numerical response, superimposed on the functional response of vertebrate feeding within a local area (Ims 1990, Hanski 1991). A dipterocarp community of a few square kilometers could not satiate these large, nomadic predators, but a sufficiently large and synchronous region would permit some local escape. If trees were asynchronous over large forest areas, withinpatch reproductive synchrony by dipterocarps would only serve to increase predation by a mobile generalist predator (Ims 1990). Bearded pig foraging behavior, therefore, should impart strong selective pressure on the dipterocarp community to be spatially synchronous in fruit fall at the spatial scale of pig migration.

The Janzen-Connell spacing model (Janzen 1970, Connell 1971; see also Schupp 1992) predicts that, as population density increases and a species becomes relatively common, individuals should suffer greater density- or frequency-dependent mortality. Within a local area, all synchronously fruiting dipterocarp species will either recruit well or lose all seeds, regardless of whether they are common or rare. This is probably due to nomadic seed predators that are not highly specific in food choice; therefore, frequencies of individual species are relatively unimportant in their foraging decisions. In addition, no monophagous pre- or postdis- 
persal insect seed predators have been documented on any of the 54 dipterocarp species at GP, despite intensive sampling during three fruiting episodes (Lyal and Curran 2000). The Janzen-Connell spacing mechanism may yet be found to be operating on a local scale of patches of reproductive individuals.

The key factor predicting the potential for seed escape was the distribution and density of the bearded pig. Pig foraging patterns may create considerable variation in the spatial distribution of dipterocarp seed destruction, resulting in regional pulses of successful dipterocarp seeding. Environmental heterogeneity in seed production, temporal pattern of fruit fall, and "ecological neighborhoods" by forest types (e.g., peat and freshwater swamp and montane areas; Levin and Paine 1974, Addicott et al. 1987, Wiens 1989) all are critical components of dipterocarp recruitment success. Because pigs have been reported to migrate over hundreds of kilometers (Pfeffer 1959, Caldecott and Caldecott 1985) and reproduce only during mast-fruiting events (Curran and Leighton 2000), censuses of pig densities from 1985 to 1993 within the Gunung Palung National Park are insufficient to determine if their populations are holding steady, declining, or increasing. Without understanding the density-dependent and density-independent processes influencing pig population dynamics and movement, the population dynamics of dipterocarp seedling recruitment across large spatial scales cannot yet be predicted.

Because of the scale of pig movement, the timing of arrival of pigs at the two sites monitored here may be a consequence of where pigs were at the onset of the mast. It remains unclear if the arrival time in a repeated experiment would be consistent with results presented here. The interspecific mast-fruiting strategy in longlived dipterocarps is highly successful for ensuring seedling regeneration, at least in some local regions in some major mast events.

Forest conversion (e.g., large-scale commercial logging of dipterocarps and establishment of industrial pulp wood plantations) alters the spatial structure of the dipterocarp (prey) populations. These activities not only may reduce local dipterocarp densities, but also may negatively affect dipterocarp regeneration across the region, including protected forest areas. To compound the complexity, linkages between the effects of large-scale intensive logging of dipterocarps in one area with the remaining forested areas of the Bornean forest ecosystem remain ambiguous. Large-scale intensive studies are urgently needed, given the rapid rate of forest conversion to industrial plantations, oil palm, and the recent forest loss to fires associated with the 1997-1998 ENSO drought and commercial land use. These ecological processes occur across the landscape and require innovative data collection at these spatiotemporal scales. Unfortunately, our understanding is highly constrained by the tremendous temporal and spatial scales and, thus, by the research logistics, of this extreme and highly threatened natural phenomenon.

\section{SUMMARY}

By experimentally manipulating the timing and distribution of seedfall, we detected that dipterocarp reproductive ecology and seedling regeneration are affected primarily by vertebrate seed predator distributions. These vertebrates and their influence on dipterocarp reproductive ecology operate across relatively large spatial scales in Bornean rain forest. The selective force of large, highly mobile vertebrate seed predators appears to have shaped dipterocarp phenology and seedfall patterns and, as a result, vertebrate ranging and reproduction. The spatial pattern of seedling and sapling survivorship results primarily from the foraging behavior of vertebrate seed predators and herbivores in the first $7 \mathrm{wk}$ post-seedfall. Seed loss by vertebrate predators had an important impact on population recruitment in late-fruiting species. An understanding of dipterocarp community (predator-prey) dynamics is essential to evaluate the effects of largescale and intensive timber extraction on landscape processes, ecosystem management, and forest regeneration.

\section{ACKNOWLEDGMENTS}

We thank the Government of Indonesia for the privilege to conduct scientific research in West Kalimantan. Several institutes and individuals facilitated and collaborated in this study and we acknowledge the following individuals for sponsoring this research: Dr. Soetikno Wirjoatmijo, Dr. Dedy Darnaedi and Dr. Rochadi Abdulhadi of the Indonesian Institute of Sciences (LIPI-PPPB), Mr. Herman Prayitno of the Indonesian Parks and Conservation (KSDA-Kalbar), and Dr. Herman Haeruman, Central Agency of Land Use Planning and Development (BAPPENAS), Bureau Chief of Natural Resources and Environment-Jakarta, and Dr. Amir of Land Use Planning and Development-West Kalimantan (BAPPEDA-Kalbar). L. M. Curran received financial support from the Biodiversity Support Program (Grant 7510), Conservation International, NSF Predoctoral Fellowship, Sigma Xi, UNESCO-MAB Young Scientist Training Program, W. Alton Jones Foundation, Wildlife Conservation Society, a Mercer Fellowship from the Arnold Arboretum of Harvard University, the University of Michigan, and the U.S. Agency for International Development. J. Bisson, M. Pearl, G. Hartshorn, A. Forsyth, C. Mackie, and especially D. McCauley made special efforts to gain institutional support for this project. Several field researchers assisted with data collection and field logistics: K. Ardlie, Abdullah, P. Budi Asmore, T. Atmowidji, Hermanto, Ismail, M. Kusneti, Morni, Sumen, Tadyn, and Utai. P. S. Ashton identified botanical and fallen leaf collections of the Dipterocarpaceae at both sites. S. Overton and J. Overton provided statistical support and wrote the computer programs for the spatial analyses. M. E. Siddall wrote computer programs for the Monte Carlo and randomization analyses. A. Dobson, B. R. Grant, P. R. Grant, S. P. Hubbell, S. Pacala, and D. Rubenstein offered constructive advice. R. S. Ostfeld, A. McEuen, S. J. Wright, two anonymous reviewers, and especially M. E. Siddall improved earlier manuscript drafts.

Literature Cited

Abacus Concepts. 1989. SuperAnova. Abacus Concepts, Berkeley, California, USA. 
Addicott, J. F., J. M. Aho, M. F. Antolin, D. K. Padilla, J. S. Richardson, and D. A. Soluk. 1987. Ecological neighborhoods: scaling environmental patterns. Oikos 49:340-346.

Aide, T. M. 1988. Herbivory as a selective agent on the timing of leaf production in a tropical understory community. $\mathrm{Na}$ ture 336:574-575.

Alexander, I. J. 1989. Mycorrhizas in tropical forests. Pages 169-188 in J. Proctor, editor. Mineral nutrients in tropical forest and savanna ecosystems. Blackwell Scientific, Oxford, UK.

Alexander, I. J., N. Ahmad, and L. S. See. 1992. The role of mycorrhizas in the regeneration of some Malaysian forest trees. Philosophical Transactions of the Royal Society of London, B. 335:379-388.

Andersen, A. N. 1989. How important is seed predation to recruitment in stable populations of long-lived perennials? Oecologia (Berlin) 81:310-315

Aptech Systems. 1993. Gauss 3.1.4. Aptech Systems, Mountain Valley, California, USA.

Ashton, P. S., T. J. Givinish, and S. Appanah. 1988. Staggered flowering in the Dipterocarpaceae: new insights into floral induction and the evolution of mast-fruiting in the aseasonal tropics. American Naturalist 132:44-66.

Augspurger, C. K. 1980. Mass-flowering of a tropical shrub (Hybanthus prunifolius): influence on pollinator attraction and movement. Evolution 34:475-488.

Augspurger, C. K. 1981. Reproductive synchrony of a tropical shrub: experimental studies on effects of pollinators and seed predators on Hybanthus prunifolius (Violaceae). Ecology 62:775-788.

Augspurger, C. K., and K. Kitajima. 1992. Experimental studies of seedling recruitment from contrasting seed distributions. Ecology 73:1270-1284.

Becker, P. 1983. Effects of insect herbivory and artificial defoliation on survival of Shorea seedlings. Pages 241-252 in S. L. Sutton, T. C. Whitmore, and A. C. Chadwick, editors. Tropical rain forest: ecology and management. Blackwell Scientific, London, UK.

Borchert, M. I., F. W. Davis, J. Michaelsen, and L. D. Oyler. 1989. Interactions of factors affecting seedling recruitment of blue oak (Quercus douglasii) in California. Ecology 70: 389-404.

Browne, F. G. 1961. The biology of Malayan Scolytidae and Platypodidae. Malayan Forest Records 22:1-255.

Burkey, T. 1994. A single-species test of Janzen's spacing mechanism. Oecologia (Berlin) 97:533-540.

Caldecott, J. O. 1986. Hunting and wildlife management in Sarawak. World Wildlife Fund Malaysia, Kuala Lumpur, Malaysia.

Caldecott, J. O., and S. Caldecott. 1985. A horde of pork New Scientist 110:32-35.

Charnov, E. L. 1976. Optimal foraging: the marginal value theorem. Theoretical Population Biology 9:129-136.

Clark, D. B., and D. A. Clark. 1984. Spacing dynamics of a tropical rain forest tree: evaluation of the Janzen-Connell model. American Naturalist 124:769-788.

Clark, D. B., and D. A. Clark. 1985. Seedling dynamics of a tropical tree: impacts of herbivory and meristem damage. Ecology 66:1884-1892.

Clark, I. 1979. Practical geostatistics. Applied Science Publishers, London, UK.

Connell, J. H. 1971. On the role of enemies in preventing competitive exclusion in some marine animals and in rain forest trees. Pages 298-310 in P. J. den Boer and G. R. Gradwell, editors. Dynamics of populations. Center for Agricultural Publishing and Documentation, Wageningen, The Netherlands.

Crawley, M. J. 1983. Herbivory: the dynamics of animalplant interactions. Blackwell Scientific, Oxford, UK.
Crawley, M. J. 1989a. Insects and plant population dynamics. Annual Review of Entomology 34:531-564.

Crawley, M. J. 1989b. The relative importance of vertebrate and invertebrate herbivores in plant population dynamics. Pages 45-71 in E. A. Bernays, editor. Insect-plant interactions. Volume I. CRC Press, Boca Raton, Florida, USA.

Crawley, M. J., and S. Pacala. 1991. Herbivores, plant parasites and plant diversity. Pages 157-174 in C. Toft, A. Aeschlimann, and L. Bolis, editors. Parasitism: conflict or coexistence. Oxford University Press, Oxford, UK.

Curran, L. M. 1992. Production forest management and practice: reviews of selected policy issues with West Kalimantan case studies. USAID-NRMP Contract Number $497-$ 0362-C-00-1064-00. Report to the Bureau Chief of Natural Resources and the Environment, in the Indonesian Central Bureau of Land-Use Planning and Development. Contract Number 497-0362-C-00-1064-00.

Curran, L. M. 1994. The ecology and evolution of mastfruiting in Bornean Dipterocarpaceae: a general ectomycorrhizal theory. Dissertation. Princeton University, Princeton, New Jersey, USA.

Curran, L. M., and M. Leighton. 2000. Vertebrate responses to spatiotemporal variation in seed production of mastfruiting Dipterocarpaceae. Ecological Monographs 70:101128.

Daljeet-Singh, K. 1974. Seed pests of some dipterocarps. Malaysian Forester 37:24-36.

Davis, F. W. 1993. Introduction to spatial statistics. Pages 17-26 in S. A. Levin, T. M. Powell, and J. H. Steele, editors. Patch dynamics. Lecture notes in mathematics 96. SpringerVerlag, New York, New York, USA.

de la Cruz, M., and R. Dirzo. 1987. A survey of the standing levels of herbivory in seedlings from a Mexican rain forest. Biotropica 19:98-106.

Duggen, A. E. 1985. Pre-dispersal seed predation by Anthocaris cardimines (Pieridae) in the population dynamics of the perennial Cardamine pratensis (Brassicaceae). Oikos 44:99-106.

Elouard, C. 1991. Regeneration of Dipterocarpaceae: some pathological aspects. Pages 165-169 in Fourth Round Table Conference of Dipterocarps. Biotrop Special Publication Number 41. Bogor, Indonesia.

Eriksson, O., and J. Ehrlen. 1992. Seed and microsite limitation of recruitment in plant populations. Oecologia (Berlin) 91:360-364.

Fenner, M. 1985. Seed ecology. Chapman and Hall, London, UK.

Fisher, R. A. 1958. Statistical methods for research workers. 13th edition. Oliver and Boyd, Edinburgh, UK.

Grubb, P. J. 1977. The maintenance of species richness in plant communities: the importance of the regeneration niche. Biological Review 52:107-145.

Hallwachs, W. 1986. Agouti (Dasyprocta punctata): the inheritors of guapinol (Hymenaea courbaril: Leguminosae). Pages 285-304 in A. Estrada and T. H. Fleming, editors. Frugivores and seed dispersal. Dr. W. Junk, Dordrecht, The Netherlands.

Hanski, I. 1991. The functional response of predators: worries about scale. Trends in Ecology and Evolution 6:141142.

Harper, J. L. 1977. Population biology of plants. Academic, London, UK.

Hart, T. B. 1995. Seed, seedling and sub-canopy survival in monodominant and mixed forests of the Ituri Forest, Africa. Journal of Tropical Ecology 11:443-459.

Howe, H. F. 1990. Survival and growth of juvenile Virola surinamensis in Panama: effects of herbivory and canopy closure. Journal of Tropical Ecology 6:259-280.

Howe, H. F. 1991. Seed dispersal by birds and mammals: implications for seedling demography. Pages 191-218 in 
K. S. Bawa and M. Hadley, editors. Reproductive ecology of tropical forest plants. Volume 7. Man and the Biosphere Series. UNESCO, Paris, France.

Howe, H. F. 1993. Aspects of variation in a neotropical seed dispersal system. Vegatatio 107/108:149-162.

Howe, H. F., E. W. Schupp, and L. C. Westley. 1985. Early consequences of seed dispersal for a neotropical tree ( $\mathrm{Vi}$ rola surinamensis). Ecology 66:781-791.

Ims, R. A. 1990. On the adaptive value of reproductive synchrony as a predator-swamping strategy. American Naturalist 136:485-498.

Janzen, D. H. 1970. Herbivores and the number of tree species in tropical forests. American Naturalist 104:501-528.

Janzen, D. H. 1971a. Seed predation by animals. Annual Review of Ecology and Systematics 2:465-492.

Janzen, D. H. 1971b. Escape of Cassia grandis L. beans from predators in time and space. Ecology 52:964-979.

Janzen, D. H. 1974. Tropical blackwater rivers, animals and mast fruiting by the Dipterocarpaceae. Biotropica 4:69103.

Janzen, D. H. 1975. Behavior of Hymenea courbaril when its predispersal seed predator is absent. Science 189:145147

Janzen, D. H. 1976. Why bamboos wait so long to flower. Annual Review Ecology and Systematics 7:47-91.

Karban, R. 1982. Increased reproductive success at high densities and predator satiation for periodical cicadas. Ecology 63:321-328.

Kelly, D. 1994. The evolutionary ecology of mast seeding Trends in Ecology and Evolution 9:465-470.

Kitajima, K., and C. Augspurger. 1989. Seed and seedling ecology of a monocarpic tropical tree, Tachigalia versicolor. Ecology 70:1102-1114.

Leighton, M., and N. Wirawan. 1986. Catastrophic drought and fire in Borneo tropical forest associated with the 1982 1983 El Niño Southern-Oscillation event. Pages 75-102 in G. T. Prance, editor. Tropical forests and the world atmosphere. American Association for the Advancement of Science, Washington, D.C., USA.

Levin, S. A. 1992. The problem of pattern and scale in ecology. Ecology 73:1943-1967.

Levin, S. A., and R. T. Paine. 1974. Disturbance, patch formation and community structure. Proceedings of the National Academy of Sciences (USA) 71:2744-2747.

Lloyd, M., and H. S. Dybas. 1966. The periodical cicada problem II. Evolution. Evolution 20:466-505.

Losos, E. 1995. Habitat specificity of two palm species: experimental transplantation in Amazonian successional forests. Ecology 76:2595-2606.

Louda, S. M. 1982a. Limitation of the recruitment of the shrub Haplopappus squarrosus (Asteraceae) by flower and seed-feeding insects. Journal of Ecology 70:43-53.

Louda, S. M. 1982b. Distribution ecology: variation in plant recruitment over a gradient in relation to insect seed predation. Ecological Monographs 52:25-41.

Lyal, C. H. C., and L. M. Curran. 2000. Seed-feeding beetles of the weevil tribe Mecysolobini (Insecta: Coleoptera: Curculionidae) developing in seeds of trees in the Dipterocarpaceae. Journal of Natural History, in press.

Marquis, R. J. 1984. Leaf herbivores decrease fitness of a tropical plant. Science 226:537-539.

McClure, H. E. 1966. Flowering, fruiting, and animals in the canopy of a tropical rain forest. Malaysian Forester 29: 182-203.

Medway, L. 1972. Phenology of tropical rain forest in Malaya. Biological Journal of the Linnean Society 4:117-146.

Moloney, K. A. 1993. Determining process through pattern reality or fantasy? Pages 61-69 in S. A. Levin, T. M. Powell, and J. H. Steele, editors. Patch dynamics. Lecture notes in mathematics 96. Springer-Verlag, New York, New York, USA.

Notman, E., D. L. Gorchov, and F. Cornejo. 1996. Effect of distance, aggregation, and habitat on levels of seed predation for two mammal-dispersed neotropical rain forest tree species. Oecologia 106:221-227.

Ostfeld, R. S., C. G. Jones, and J. O. Wolff. 1996. Of mice and mast: ecological connections in eastern deciduous forests. BioScience 46:323-330.

Pfeffer, P. 1959. Biologie et migrations du sanglier de Borneo (Sus barbatus Müller 1869). Mammalia 23:277-303.

Pickett, S. T. A., J. Kolasa, and C. G. Jones. 1994. Ecological understanding: the nature of theory and the theory of nature. Academic Press, New York, New York, USA.

Pyke, D. A., and J. N. Thompson. 1986. Statistical analysis of survival and removal rate experiments. Ecology 67:240245.

Salafsky, N. 1994. Drought in the rain forest: effects of the 1991 El Niño-Southern Oscillation event on a rural economy in West Kalimantan, Indonesia. Climate Change 27: 373-396.

Salisbury, E. J. 1942. The reproductive capacity of plants. Bell, London, UK.

Schupp, E. W. 1988. Seed and early seedling predation in the forest understory and in treefall gaps. Oikos 51:71-78.

Schupp, E. W. 1992. The Janzen-Connell model for tropical tree diversity: population implications and the importance of spatial scale. American Naturalist 140:526-530.

Schupp, E. W., and E. J. Frost. 1989. Differential predation of Welfia georgii seeds in treefall gaps and the forest understory. Biotropica 21:200-203.

Sheil, D., and R. M. May. 1996. Mortality and recruitment rate evaluations in heterogeneous tropical forests. Journal of Ecology 84:91-100.

Silvertown, J. 1980. The evolutionary ecology of mast seeding in trees. Biological Journal of the Linnean Society 14: $235-250$.

Smith, T. J., III. 1987. Seed predation in relation to tree dominance and distribution in mangrove forests. Ecology 68:266-273.

Smith, T. J., III, H. T. Chan, C. C. McIvor, and M. B. Robblee. 1989. Comparisons of seed predation in tropical tidal forests from three continents. Ecology 70:146-151.

Smits, W. T. M., I. Yasman, D. Leppe, and M. Noor. 1991. Some observations on diseases of Dipterocarpaceae. Pages 147-163 in Biotrop Special Publication Number 41. Fourth Round Table Conference of Dipterocarps. Bogor, Indonesia.

Sokal, R. R., and N. Oden. 1978a. Spatial autocorrelation in biology 1. Methodology. Biological Journal of the Linnean Society 10:199-228.

Sokal, R. R., and N. Oden. 1978b. Spatial autocorrelation in biology 2. Some biological implications and four applications of evolutionary and ecological interest. Biological Journal of the Linnean Society 10:229-249.

Sork, V. L. 1987. Effects of predation and light on seedling establishment in Gustavia superba. Ecology 68:1341-1350.

Sweeney, B. W., and R. L. Vannote. 1982. Population synchrony in mayflies: a predator satiation hypothesis. Evolution 36:810-821.

SYSTAT. 1992. Version 5.2 edition. SYSTAT, Evanston, Illinois, USA.

Taylor, R. J. 1984. Predation. Chapman and Hall, London, UK.

Terborgh, J., E. Losos, M. P. Riley, and M. Bolaños Riley. 1993. Predation by vertebrates and invertebrates on the seeds of five canopy tree species of an Amazonian forest. Vegetatio 107/108:375-386.

van Es, H. M. 1993. The spatial nature of soil variability and its implications for field studies. Pages $27-36$ in S. A. Levin, T. M. Powell, and J. H. Steele, editors. Patch dynamics. 
Lecture notes in mathematics 96. Springer-Verlag, New York, New York, USA.

van Schaik, C. P., J. W. Terborgh, and S. J. Wright. 1993. The phenology of tropical forests: adaptive significance and consequences for primary consumers. Annual Review of Ecology and Systematics 24:353-377.

Waller, D. M. 1979. Models of mast-fruiting in trees. Journal of Theoretical Biology 80:223-232.

Webb, C. O., and L. M. Curran. 1996. Field key to the dipterocarp seedlings of the Gunung Palung National Park, West Kalimantan, Indonesia. Tropical Biodiversity 3:193-225.

Webb, S. L., and M. F. Willson. 1985. Spatial heterogeneity in post-dispersal predation on Prunus and Uvularia seeds. Oecologia (Berlin) 67:150-153.
Whelan, C. J., M. F. Willson, C. A. Tuma, and I. Souza Pinto. 1991. Spatial and temporal patterns of post-dispersal seed predation. Canadian Journal of Botany 69:428-436.

Wiens, J. A. 1989. Spatial scaling in ecology. Functional Ecology 3:385-397.

Wiens, J. A., J. F. Addicott, T. J. Case, and J. Diamond. 1986. Overview: the importance of spatial and temporal scale in ecological investigations. Pages 145-153 in J. Diamond and T. Case, editors. Community ecology. Harper and Row, New York, New York, USA.

Williams, K. S., K. G. Smith, and F. M. Stephen. 1993. Emergence of 13-yr periodical cicadas (Cicadidae: Magicicada): phenology, mortality, and predator satiation. Ecology 74: $1143-1152$. 